University of South Florida

DIGITAL COMMONS

@ UNIVERSITY OF SOUTH FLORIDA
Digital Commons @ University of

South Florida

\title{
$2-9-2018$
}

\section{Public Transit in America 2017}

CUTR

Follow this and additional works at: https://digitalcommons.usf.edu/cutr_nctr

\section{Recommended Citation}

"Public Transit in America 2017," National Center for Transit Research (NCTR) Report No. CUTR-NCTRRR-2018-08, Center for Urban Transportation Research, University of South Florida, 2018.

DOI: https://doi.org/10.5038/CUTR-NCTR-RR-2018-08

Available at: https://scholarcommons.usf.edu/cutr_nctr/8

This Technical Report is brought to you for free and open access by the National Center for Transit Research (NCTR) Archive (2000-2020) at Digital Commons @ University of South Florida. It has been accepted for inclusion in Research Reports by an authorized administrator of Digital Commons @ University of South Florida. For more information, please contact digitalcommons@usf.edu. 
Final Report CUTR-2019-08

\title{
Public Transit in America
}

\author{
Observations from the
}

\section{National Household Travel Survey}

\author{
Prepared For:
}

National Center for Transit Research

at the Center for Urban Transportation Research

\author{
Prepared By: \\ Jodi Godfrey \\ Steven E. Polzin \\ Tyler Roessler
}


The contents of this report reflect the views of the authors, who are responsible for the facts and the accuracy of the information presented herein. This document is disseminated under the sponsorship of the U.S. Department of Transportation's University Transportation Centers Program, in the interest of information exchange. The U.S. Government assumes no liability for the contents or use thereof.

Special acknowledgement goes to two graduate students that assisted in the data analysis portion of the report prior to graduation, Richard Driscoll and Kurt Lehmann 


\section{Public Transit in America}

\section{Observations from the 2017 National Household Travel Survey}

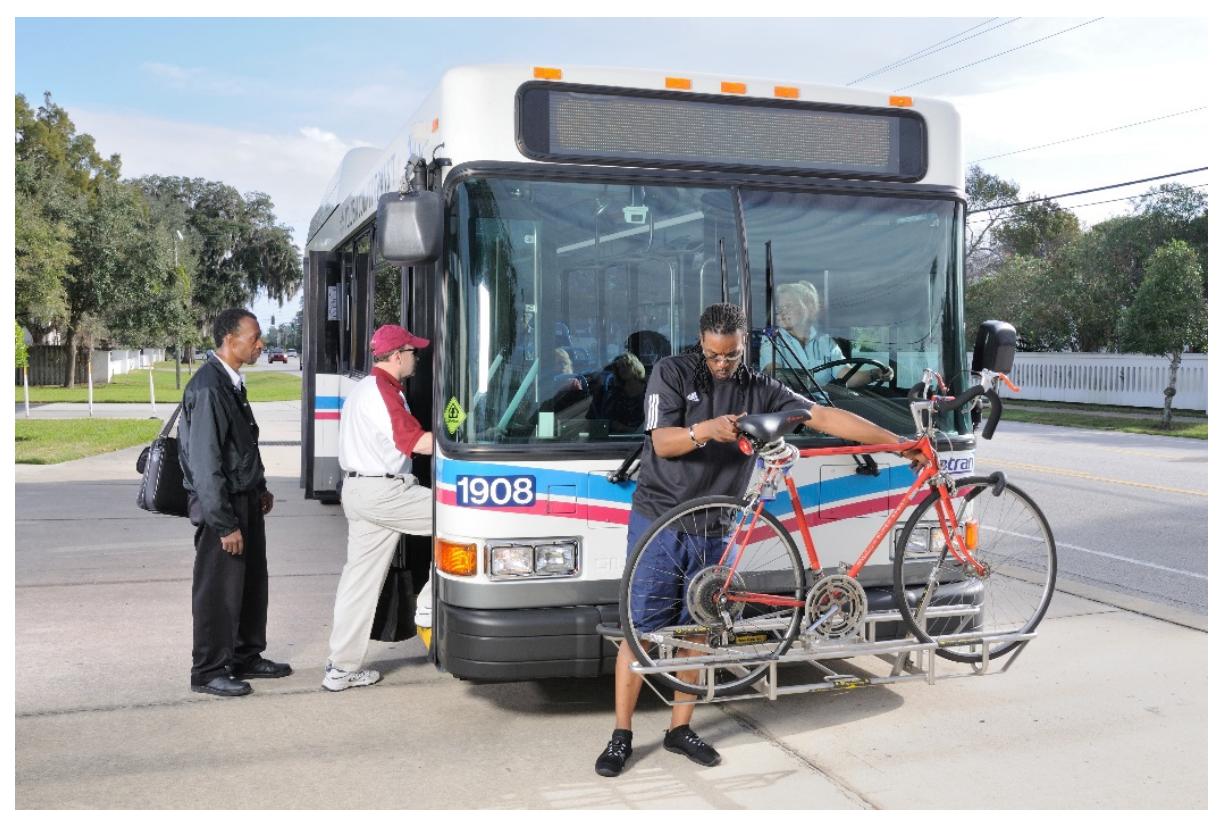

August 2019 


\begin{tabular}{|c|c|c|c|c|}
\hline \multicolumn{5}{|c|}{ Technical Report Documentation Page } \\
\hline 1. Report No. & \multicolumn{2}{|c|}{ 2. Government Accession No. } & \multicolumn{2}{|c|}{ 3. Recipient's Catalog No. } \\
\hline \multirow{2}{*}{\multicolumn{3}{|c|}{$\begin{array}{l}\text { 4. Title and Subtitle } \\
\text { Public Transit in America: Observations from the } 2017 \text { National } \\
\text { Household Travel Survey }\end{array}$}} & \multicolumn{2}{|l|}{$\begin{array}{l}\text { Five. Report Date } \\
\text { May } 2019\end{array}$} \\
\hline & & & \multicolumn{2}{|c|}{$\begin{array}{l}\text { 6. Performing Organization Code } \\
\text { CUTR, University of South Florida }\end{array}$} \\
\hline \multicolumn{3}{|c|}{$\begin{array}{l}\text { 7. Author(s) } \\
\text { Jodi Godfrey, Steven Polzin, Tyler Roessler }\end{array}$} & \multicolumn{2}{|c|}{ 8. Performing Organization Report No. } \\
\hline \multirow{2}{*}{\multicolumn{3}{|c|}{$\begin{array}{l}\text { 9. Performing Organization Name and Address } \\
\text { Center for Urban Transportation Research } \\
\text { University of South Florida } \\
4202 \text { E Fowler Ave, } \\
\text { Tampa, FL } 33620\end{array}$}} & \multicolumn{2}{|l|}{ 10. Work Unit No. (TRAIS) } \\
\hline & & & \multicolumn{2}{|l|}{ 11. Contract or Grant No. } \\
\hline \multirow{2}{*}{\multicolumn{3}{|c|}{$\begin{array}{l}\text { 12. Sponsoring Agency Name and Address } \\
\text { NCTR }\end{array}$}} & \multicolumn{2}{|c|}{$\begin{array}{l}\text { 13. Type of Report and Period Covered } \\
\text { Final Report } \\
\text { May } 2019\end{array}$} \\
\hline & & & \multicolumn{2}{|c|}{ 14. Sponsoring Agency Code } \\
\hline \multicolumn{5}{|l|}{ 15. Supplementary Notes } \\
\hline \multicolumn{5}{|c|}{ 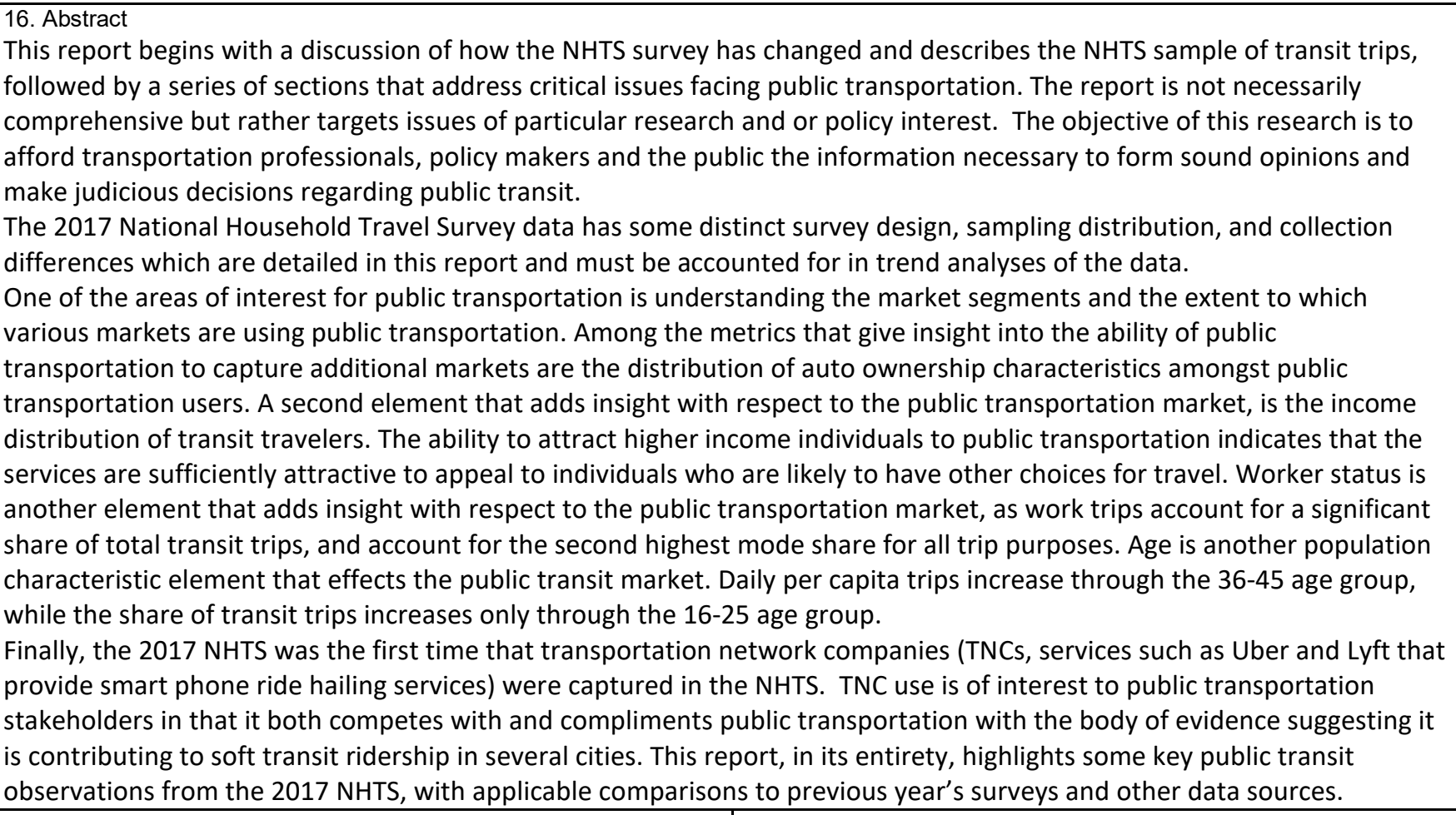 } \\
\hline \multicolumn{2}{|c|}{$\begin{array}{l}\text { 17. Key Word } \\
\text { public transportation, ridership, market profile, NHTS }\end{array}$} & \multicolumn{3}{|c|}{$\begin{array}{l}\text { 18. Distribution Statement } \\
\text { No Restrictions }\end{array}$} \\
\hline $\begin{array}{l}\text { 19. Security Classif. (of this report) } \\
\text { Unclassified }\end{array}$ & $\begin{array}{r}\text { 20. Security Classif } \\
\text { Unclas }\end{array}$ & $\begin{array}{l}\text { of this page) } \\
\text { fied }\end{array}$ & $\begin{array}{c}\text { 21. No. of Pages } \\
46\end{array}$ & 22. Price \\
\hline
\end{tabular}

Form DOT F 1700.7 (8-72) Reproduction of completed page authorized




\section{Executive Summary}

The 2017 NHTS has some distinct survey design, sampling distribution, and collection differences, which are explored prior to delving into the transit market characteristics. The 2017 NHTS is an address-based sample survey, which is distributed on a national level. In addition, there were 13 add-on areas, which were purchased by State Departments of Transportation or Metropolitan Planning Organizations. While the 2017 NHTS maintained the two-phase structure of the survey, a household recruitment and subsequent person level retrieval survey, the 2017 NHTS survey process was different than in past surveys. Previous NHTS surveys used Random Digit Dial (RDD) telephone sampling and only Computer-Assisted Telephone Interview (CATI) data collection, while the 2017 NHTS changed to Address Based Sampling (ABS) with mail-back as the primary recruitment survey response mode.

Since the 2017 NHTS collected data from a sample rather than the census of all households, all persons, and all travel they made during the data period is subject to sampling error. The size of sampling error depends largely on the size of the sample, i.e., the number of households and the number of persons in each sampled household in the final sample. Since the sample size becomes smaller as one moves to smaller geographies, or to smaller population segments at a given geography, sampling error in data for a given characteristic, in general, is smallest at the national level and at the full population level for a given geography. Sampling error increases as one moves to smaller geographies or smaller population segments at a given geography. This becomes relevant for non-auto modes where the shares of travel on the respective modes limit the amount of data available.

Given changes in survey methods and more limited resources available for analysis, this report is structured differently than previous CUTR NHTS reports - less of a systematic analysis of public transportation travel and travelers and more of an exploration of key strategic issues relevant to public transportation's future. The report is not necessarily comprehensive but rather targets issues of particular research and or policy interest. The objective of this research is to afford transportation professionals, policy makers and the public the information necessary to form informed opinions and make judicious decisions regarding public transit.

Public transportation has historically constituted approximately $2 \%$ of trips by household members in the U.S., a relatively modest share of all travel, making public transportation survey information particularly sensitive to sample sizes and the weighting strategies used for developing national estimates from survey data. More specifically, one of the concerns with the sample of transit trips relates to the fact that the transit travel choice is different than bike, walk, and drive choices in that the propensity to use transit is significantly influenced by the availability of service in the geography of the traveler. This availability of travel choice issue has 
significant variation across geography for public transportation because public transit is not ubiquitous as the level of service is highly influenced by geographic characteristics such as urban area size, density, and local decision making. The relevance of this differential transit availability is important due to the non-uniform sampling rates across geography that are inherent in a survey strategy that has add-on samples. This observation is not intended to discredit all that can be gleaned from available data but it is shared as a caution to analysts. Similarly, with respect to public transportation, this phenomenon is not unique to the 2017 survey but is relevant to prior surveys as well.

Survey results indicated that public transit mode share increased from $2.0 \%$ in 2009 to $2.54 \%$ in 2017 , an increase of approximately $27 \%$ in mode share. This mode share increase was curious in the context of the fact that actual transit ridership counts declined approximately $4 \%$ between the respective survey periods in spite of growing population and expanded service. Ridership has declined an additional approximate 4\% since the 2017 NHTS survey, according to the National Transit Database (NTD).

One area of interest for public transportation policy makers is the understanding of market segments and the extent to which various markets are using public transportation. Among the metrics that give insight into the ability of public transportation to capture additional markets are the distribution of auto ownership characteristics and income levels amongst public transportation users. The zero-vehicle household component of the market has been almost half of all riders over the past three survey cycles. The share of travel by this segment has remained high but has declined modestly with the most recent survey. An analysis of zerovehicle household transit use by income quintile reveals that zero-vehicle households that make transit trips, might have adequate resources to own vehicles, but may have chosen to forgo vehicle ownership. The ability to attract higher income individuals to public transportation indicates that the services are sufficiently attractive to appeal to individuals who are likely to have other choices for travel. There has been meaningful growth in the share of transit riders who come from higher income households, most significantly in the rail mode. This is indicative of numerous factors including the prevalence of higher incomes in some of the larger Metropolitan areas that provide rail services and reflects the fact that these services typically offer higher speed travel and often cater to destinations such as central business districts and airports that are frequent destinations for higher income individuals.

Worker status is another element that adds insight with respect to the public transportation market, as work trips account for a significant share of total transit trips, and account for the second highest mode share for all trip purposes. Age is another population characteristic element that effects the public transit market. Daily per capita trips increase through the 36-45 age group, while the share of transit trips increases only through the 16-25 age group. 
The NHTS data set provides an opportunity to gain insight on Transportation Network Company (TNC) users and begin to explore interrelationships between public transportation and TNC use. Top transit cities are also top cities for TNC use. The conditions conducive to not using personal vehicles such as very high-priced parking and being away from home on business travel, make alternatives such as TNC and public transportation more viable. TNC use has a somewhat similar age profile as does transit use but has particularly gained market share for business- and business-related travel. In instances where personal auto travel is disadvantageous, TNC and public transportation will be competitors for travelers' business. TNCs primary opportunities to be complementary are in cases where they serve as first-mile/last-mile connectors or contract operators/providers for targets markets such as paratransit services. In a more general context, TNCs have the potential to be complementary to public transit in cases where they result in households relinquishing a vehicle or vehicles such that public transit becomes a more competitive option in more travel situations.

Finally, travel speed is a critical factor in mode choice and, not surprisingly, roadway speeds have declined since prior survey years. The evidence on transit speeds is mixed with bus slowing some and rail getting a little faster. The comparative data on the components of overall travel time on transit shows that the largest share of the increase in average transit trip times between 2009 and 2017 is attributable to in-vehicle travel time. Access and egress times also increased on average from 2009, but the average wait time decreased slightly. The overall transit travel time increased $13.8 \%$ in 2017.

The collective consequence of the information presented suggests analysts continue to monitor evolution of transit markets and transit's competitiveness going forward. The data provides some strong evidence of changes in transit markets that appear consistent with broader socioeconomic and demographic phenomenon and transit service deployment initiatives in recent years. These changes may have implications with respect to policies that influence the pricing, funding and service allocations for public transportation. 


\section{Table of Contents}

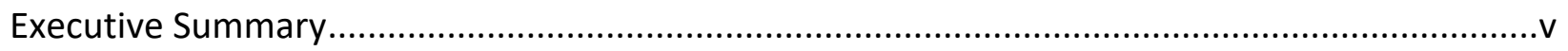

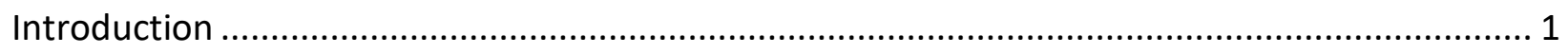

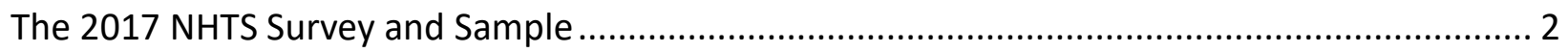

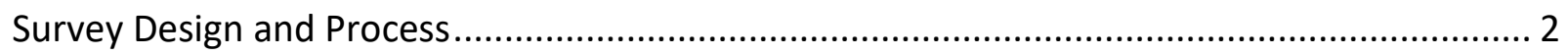

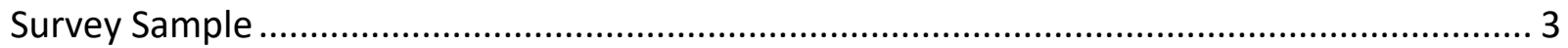

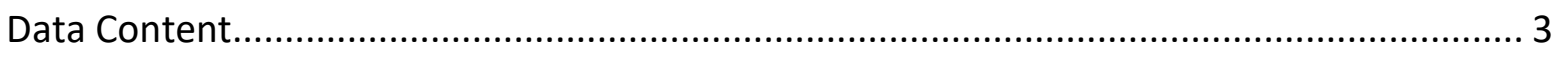

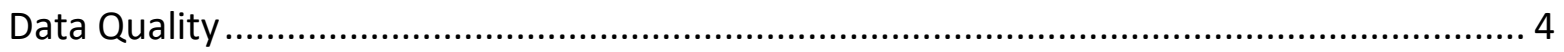

What We Know about the 2017 NHTS Transit Sample....................................................... 6

Who's Using Public Transit -The Demographic Profile of Transit Users ................................. 10

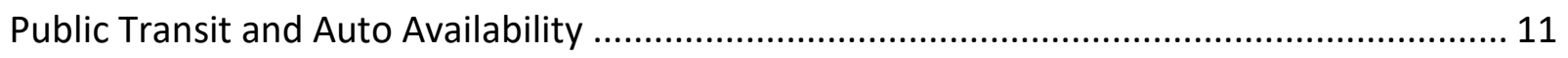

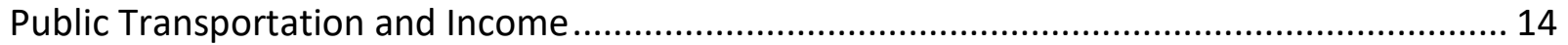

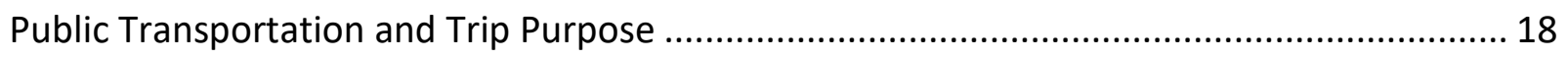

Public Transportation and Worker Status......................................................................... 20

Public Transportation and Home Ownership............................................................. 21

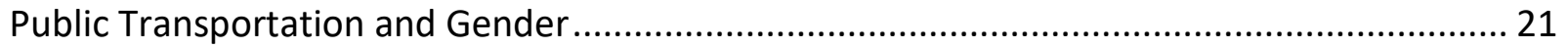

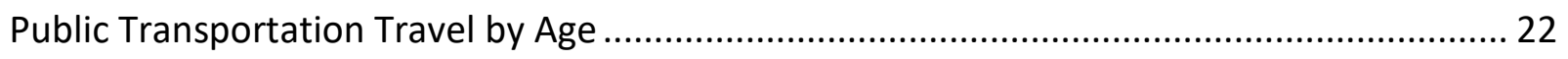

Public Transportation Race/Ethnicity Distribution ........................................................ 24

Public Transportation and Urban Classification Distribution........................................... 25

Public Transit and Transportation Network Company Travel (TNC)................................... 25

How Competitive Is Public Transportation? ................................................................... 31

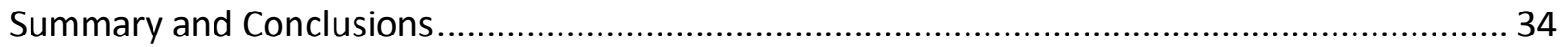

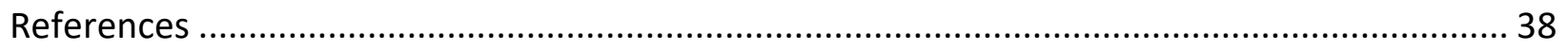




\section{List of Figures}

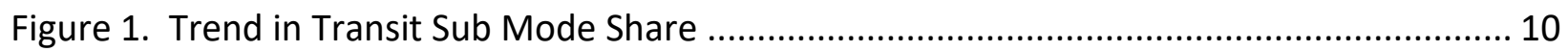

Figure 2. Share of Transit Trips by Household Vehicle Availability .......................................... 11

Figure 3. Public Transit Trip Share by Worker and Vehicle Availability, 2009........................... 12

Figure 4. Public Transit Trip Share by Worker and Vehicle Availability, 2017.......................... 13

Figure 5. Transit Share of Total Trips by Worker Auto Availability Relationship........................ 13

Figure 6. Per Capita Annual Transit Trips by Household Vehicle Availability ............................. 14

Figure 7. Commute Mode Share by Income, 2017 .................................................................. 16

Figure 8. Transit User Sub Mode Split by Income Quintiles and Survey Year ........................... 16

Figure 9. NHTS Transit Trips by Income Quintile ................................................................ 17

Figure 10. 2017 ACS Commuting Mode Share by Income and Transit Sub Mode ..................... 17

Figure 11. Trip Purpose Distribution Trend for Public Transit Trips .......................................... 19

Figure 12. Transit Share of Total Trips by Household Worker Count, 2017 ............................. 19

Figure 13. Transit Trips by Trip Purpose, 2017 ................................................................... 20

Figure 14. Share of Transit Trips by Household Worker Count, 2017 ..................................... 20

Figure 15. Public Transit Share of Trips by Home Ownership ................................................ 21

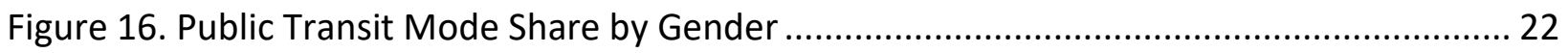

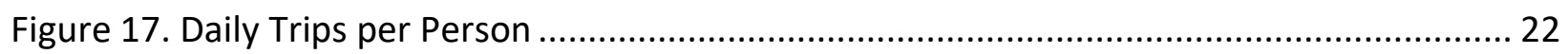

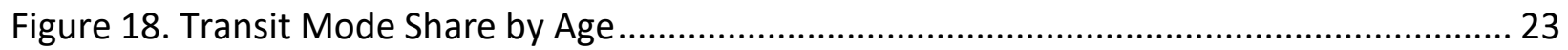

Figure 19. Share of Transit Trips by Age Group .................................................................. 23

Figure 20. Share of Transit Trips by Age Group, 2017 .......................................................... 24

Figure 21. Percent of Transit Trips by Race ........................................................................... 25

Figure 22. Public Transit Mode Share by Urban Classification .............................................. 25

Figure 23. Share of Total Trips Made on "Taxi" Mode by Age Group .................................... 27

Figure 24. Share of All Taxi/TNC Trips by Age, 2017............................................................ 27

Figure 25. Transit and TNC Mode Share of Total Trips by Age Group, 2017 ............................ 28

Figure 26. Share of TNC/Transit Trips by Age Group, 2017.................................................... 28

Figure 27. Trip Purpose Distribution Trend for Taxi/TNC Trips ................................................. 29

Figure 28. Mode Share Distribution for TNC and Transit Trips by Trip Purpose, 2017 .............. 29

Figure 29. Trip Purpose Distribution Trend for Public Transit Trips ........................................ 30

Figure 30. Share of Public Transit Users Who Used Rideshare App in Past 30 Days, 2017......... 30

Figure 31. Average Transit Travel Time Components, 2009 to 2017 Comparison ....................... 31

Figure 32. Average Transit Travel Time Components for Trips by Transfers, 2017 ................... 32

Figure 33. Average Transit Trip Speed Trend by Metro Area Size ........................................... 33

Figure 34. Roadway Trip Speed Trend by Metro Area Size ..................................................... 33

Figure 35. Transit Trip Speed by Sub Mode, 2017 ................................................................ 34

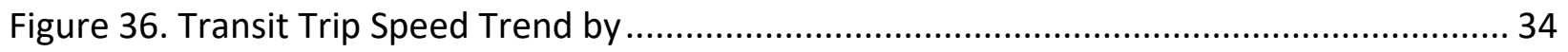




\section{List of Tables}

Table 1. Sampling Error of Annual Transit Trips for Selected Population Segments ................... 5

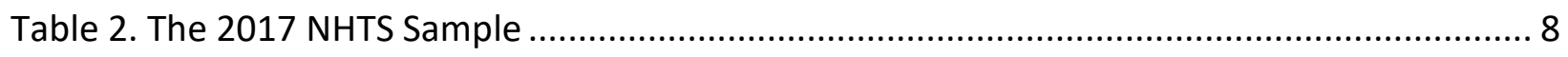

Table 3. Transit Mode Share Comparisons ............................................................................ 9

Table 4. Zero-Vehicle Household Transit Use by Income Quintile (Percent of all Transit Trips) . 11

Table 5. Share of Owner vs. Renter Occupied Housing ......................................................... 21

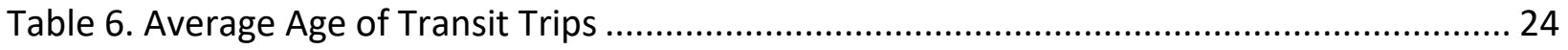




\section{Introduction}

Since early in the history of the National Household Travel Survey (NHTS), the Center for Urban Transportation Research (CUTR) has used this data resource as a means of gathering a richer understanding of transit ridership and travel behavior in America. As the preeminent national survey of travel behavior, the NHTS and its predecessor surveys have been an invaluable source of information on transit use and the characteristics of transit travel and travelers. Among the outputs of prior CUTR research were major reports following prior survey releases including:

An Assessment of Public Transportation Markets Using NHTS Data, prepared for the Florida Department of Transportation (2012).

Public Transit in America: Analysis of Access Using the 2001 National Household Travel Survey, prepared for the Florida Department of Transportation, December 2006.

Public Transit in America: Results from the 2001 National Household Travel Survey, Final Report, National Center for Transit Research (2005).

Public Transit in America: Findings from the 1995 Nationwide Personal Transportation Survey, National Urban Transit Institute (1998).

In addition, numerous more targeted papers and reports have been produced exploring particular critical issues for public transportation. With the release of the 2017 NHTS, there is a similar opportunity to explore what new lessons might be learned based on those survey results. Given changes in survey methods and more limited resources available for analysis, this report is structured differently - less of a systematic analysis of public transportation travel and travelers and more of an exploration of key strategic issues relevant to public transportation's future.

This report begins with a discussion of how the NHTS survey has changed and describes the NHTS sample of transit trips. This is followed by a series of sections that address critical issues facing public transportation. The report is not necessarily comprehensive but rather targets issues of particular research and policy interest.

Subsequent report sections include the following:

The 2017 NHTS Survey and Sample

What We Know about the 2017 NHTS Transit Sample

Who's Using Public Transit -The Demographic Profile of Transit Users

Public Transit and Transportation Network Company Travel (TNC)

How Competitive Is Public Transportation?

Summary and Conclusions 


\section{The 2017 NHTS Survey and Sample}

\section{Survey Design and Process}

The 2017 NHTS is an address-based sample survey, which is distributed on a national level. In addition, there were 13 add-on areas, which were purchased by State Departments of Transportation or Metropolitan Planning Organizations. Those 13 areas included the states of Arizona, California, Georgia, Maryland, New York, North Carolina, South Carolina, Texas, and Wisconsin, and the MPOs of Dallas-Ft. Worth TX, Des Moines IA, Tulsa OK, and Waterloo IA. (NHTS Users Guide, 2018).

While the 2017 NHTS maintained the two-phase structure of the survey, a household recruitment and subsequent person level retrieval survey, the 2017 NHTS survey process was different than in past surveys. Previous NHTS surveys used Random Digit Dial (RDD) telephone sampling and only Computer-Assisted Telephone Interview (CATI) data collection, while the 2017 NHTS changed to Address Based Sampling (ABS) with mail-back as the primary recruitment survey response mode (NHTS Users Guide, 2018). More information regarding the survey design and process can be found at https://nhts.ornl.gov.

Other key methodological changes that occurred between the 2009 NHTS survey and the 2017 NHTS survey, aside from the sample frame and recruit changes mentioned previously. The definition of a usable household changed from requiring complete travel logs of $50 \%$ of adults in the household in 2009 to requiring 100\% of household members over 5 years old for the 2017 survey. In 2009, trip distances were self reported, while the 2017 survey used a networkcoded shortest path distance as calculated from the addresses of the start and end destination of each trip. Finally, in 2017 the CATI option was supported by a web-based self-report tool, which was not available for any previous survey years.

Preliminary evaluations of the data collection differences revealed that trip rates continued their declining trend from previous years, while trip distance needed to be adjusted to allow for comparisons between previous years. The adjustment factors were considered in the data analysis for this report. The data also revealed that transit trips were high and vehicle trips were low, which resulted in additional funding to be invested to discern why those changes occurred. The change in trip definition, which allows for trips to start and end at the same location in 2017 resulted in a break in walk and bike trends, possibly due to under-reporting of short non-purposeful trips. ${ }^{1}$

\footnotetext{
${ }^{1}$ McGuckin, Nancy and Fucci, Anthony. Summary of Travel Trends: Findings from the 2017 NHTS. http://onlinepubs.trb.org/onlinepubs/Conferences/2018/NHTS/McGuckinTravelTrends.pdf
} 


\section{Survey Sample}

The 2017 NHTS contains a large sample size of 129,696 households for the U.S., consisting of 26,099 national households and 103,597 additional households from add-on partners that are mentioned previously. It collected data from a given sample household on all travel made in a 24- hour period (i.e., the designated travel day for this household) by persons 5 years of age or older for all purposes by all means of transportation. The sampled households cover all areas of the U.S., both urban and rural, and the designated travel day for different sampled households varies throughout the 14-month period from April 2016 to May 2017. Detailed trip data were collected through telephone interviews or web response options. The data include weights to expand the sample to annual totals. Details about this survey and the datasets from it can be found at the official NHTS website of the Federal Highway Administration (FHWA, 2018).

\section{Data Content}

The previously referenced NHTS User Guide ${ }^{2}$ provides several definitions of various travel concept terms including:

- Trip - representation of a start and end movement from location to location by any mode of transportation, including cases where the start and end location are coincident.

- Person trip - a trip by one person using any mode of transportation, with each record representative of one individual trip file.

- Person Miles of Travel (PMT) - the number of miles traveled by each person on a trip.

The 2017 NHTS collected data, divided into two schemes, the one-way trips and round-trips that the sampled persons and households took on their designated travel days. A one-way trip is defined as any time a subject went from one address to another for purposes other than changing the mode. Any one-way trip is a linked trip from its origin to its destination for any mode, particularly for transit. A one-way trip is frequently referred to as a person-trip in this study. A round-trip purpose scheme is derived from the trip purpose survey responses, which is necessary in order to compare the NHTS trip purpose to previous Nationwide Personal Transportation Survey (NPTS).

The 2017 NHTS collected data on many characteristics for each one-way trip in the survey: trip distance, trip duration, trip purpose, and the modes of transportation, among other things. A total of 20 specific modes are recognized in the survey. If more than one mode is used on a one-way trip, the mode that covered the most distance is designated as the main mode for that trip. The 2009 NHTS survey recognized a total of 24 specific modes, some of which were

\footnotetext{
${ }^{2}$ https://nhts.ornl.gov/assets/2017UsersGuide.pdf
} 
combined in the modes defined for the 2017 survey such as public bus and commuter bus, Amtrak and commuter rail, and subway and streetcar.

A transit trip is a person-trip whose main mode is transit. For this study, transit consists of any of the following fixed-route modes identified in the 2017 NHTS: public or commuter bus, Amtrak/ commuter rail, subway/elevated/light rail/streetcar. The data for transit trips includes wait time for transit vehicles. If a transit trip involves more than one boarding, it is unclear from the survey documents whether the wait time is for the first boarding only or for all boardings. The data for transit trips also includes information on the specific mode for each of up to five access segments and on the specific mode for each of up to five egress segments. However, the data do not include the access or egress duration for each access or egress segment; rather, they include only the combined total access time for all access segments and the combined total egress time for all egress segments. For any transit trip, it is unclear from the survey documents whether its main mode portion contains a single boarding or may contain multiple boardings with the same transit mode.

The 2017 NHTS also collected data on the personal, household, and location characteristics of the persons and households in the sample. Relevant to the current study are person age; and whether a person was a driver. It also contains data on many household characteristics. Relevant to the current study are annual household income, vehicles available for use by household members, and race and ethnicity.

The 2017 NHTS collected data on general travel habits of the persons in the sample. These include frequency of transit use during the month immediately before the travel day and weekly frequency of walking and biking.

\section{Data Quality}

Just like any data obtained through a probability-based sample, the data presented in this study contain at least two types of errors: sampling and non-sampling.

Since the 2017 NHTS collected data from a sample rather than the census of all households, all persons, and all travel they made during the data period, the data presented may differ from what would have been obtained if a census were conducted. The size of sampling error depends largely on the size of the sample, i.e., the number of households and the number of persons in each sampled household in the final sample. Since the sample size becomes smaller as one moves to smaller geographies, or to smaller population segments at a given geography, sampling error in data for a given characteristic, in general, is smallest at the national level and at the full population level for a given geography. Sampling error increases as one moves to smaller geographies or smaller population segments at a given geography. 
This report does not show sampling error for presentation clarity. Showing sampling error along with the data of interest would not be an issue for presentation if the amount of data of interest were limited. In this report, however, a large amount of data of interest is presented, making it impractical to show the sampling error as well. Showing the sampling error would double the number of columns or the number of rows for data presented in a table format.

To avoid presenting data whose sampling error is unreasonably large, the current study avoids presenting data that result from small samples. This is accomplished by limiting the analyses to large sub-nation geographies, by limiting the analyses to a small number of population segments at these large geographies for any given characteristic considered, and by choosing break points between population segments so that each segment has an adequate portion of the sample. Estimates of sampling error are presented for a few data items to give the reader a direct appreciation of the likely size of sampling error for the various transit markets presented. Table 1 shows the sampling error of the annual number of transit trips estimated from the 2009 NHTS for five population segments, ranging from the full U.S. population to the U.S. population segments by vehicle availability and driver status, as well as to the full population. For each segment, the table shows its sample size in the number of linked transit trips, the estimated number of transit trips, and three measures of sampling error. These measures include the $95 \%$ margin of error, standard error, and coefficient of variation (COV). The COV indicates the size of sampling error relative to the estimated number of trips in percentage terms.

Table 1. Sampling Error of Annual Transit Trips for Selected Population Segments

\begin{tabular}{|l|r|r|r|r|r|}
\hline Population Segments & Sample & $\begin{array}{l}\text { Estimated } \\
\text { Transit Trips } \\
\text { (millions) }\end{array}$ & $\begin{array}{l}\text { 95\% Margin } \\
\text { of Error } \\
\text { (millions) }\end{array}$ & $\begin{array}{l}\text { Standard } \\
\text { Error } \\
\text { (millions) }\end{array}$ & $\begin{array}{l}\text { Coefficient of } \\
\text { Variation } \\
\text { (COV) }\end{array}$ \\
\hline U.S. total & 11,090 & 9,445 & 421.88 & 215.2 & $2.3 \%$ \\
\hline $\begin{array}{l}\text { U.S. zero-vehicle households } \\
\text { U.S. non-drivers }\end{array}$ & 4,314 & 4,309 & 282.6 & 144.2 & $3.3 \%$ \\
\hline $\begin{array}{l}\text { U.S. non-drivers in zero-vehicle } \\
\text { households }\end{array}$ & 2,908 & 2,865 & 256.8 & 131.0 & $3.3 \%$ \\
\hline $\begin{array}{l}\text { Source: Data on sample size, estimated transit trips, and 95\% margin of error are from Table Designer at the } \\
\text { official NHTS website. Standard error } \\
\text { error / estimated transit trips). }\end{array}$ & $45 \%$ margin of error / 1.96. Coefficient of variation = 100 * (standard \\
\hline
\end{tabular}

Except for some of the numbers in this table, all other numerical results in this report have been estimated by the author using the weighted datasets from the $2017 \mathrm{NHTS}$. The COV is 2.3\% for the full U.S. population, indicating that the standard error for the estimated number of transit trips for the U.S. as a whole is $2.3 \%$ of the estimate. The COV is slightly higher at 3.3\% for all transit trips made by persons in zero-vehicle households, although the sample is smaller than $40 \%$ of the full U.S. sample. 


\section{What We Know about the 2017 NHTS Transit Sample}

Public transportation has historically constituted approximately $2 \%$ of trips by household members in the U.S. and comprised approximately $5 \%$ of work trip commuting. This relatively modest share of all travel results in public transportation information being particularly sensitive to survey sample sizes and the weighting strategies used for developing national estimates from survey data. The 2017 NHTS included completed surveys from 129,696 U.S. households out of a total of $118,028,251$ representing $0.11 \%$ of total households (Census Bureau Table B25001, 2016). The survey sample produced over 11,000 transit linked trip records, which is well less than $1 / 10$ of $1 \%$ of daily transit use. Even with state of the practice data processing and weighting, the sample of transit trips is admittedly modest and merits caution by analysts using the data.

More specifically, one of the concerns with the sample of transit trips relates to the fact that the transit travel choice is different than bike, walk, and drive choices in that the propensity to use transit is significantly influenced by the availability of service in the geography of the traveler (both origin destination). This availability of travel choice issue has significant variation across geography for public transportation because public transit is not ubiquitous as the level of service is highly influenced by geographic characteristics such as urban area size and density. This differs from drive and ride options where, for example, roadway availability is nearly ubiquitous with virtually every parcel of land having roadway access. This consideration becomes relevant because the sample weighting is based on sociodemographic characteristics and the availability of public transportation as a travel option is not a factor used in sample weighting. Thus, the sample plan including the integration of add-on samples collected disproportionately to the national population, does not assure that the probability of the level of service of transit available to the resultant weighted survey population is representative of aggregate national conditions. In layman language, if more persons are sampled in urban areas with quality transit, there would be a propensity for higher transit use to be reflected in the survey results, even with appropriate weighting for sociodemographic characteristics.

This phenomenon of differential availability of travel options is a relevant consideration for future national travel survey sampling plan designs. While traditional travel surveys were not as sensitive to this consideration due to the ubiquitous availability of the travel options (drive, ride with other, walk, bike, etc.) increasingly, the travel choice set is influenced by urban characteristics independent of sociodemographic characteristics of the population. Public transportation exemplifies that difference, as it is a far more competitive option in dense urban areas who have been willing to invest in quality services. Other travel options, for example transportation network companies (TNCs) are similarly not uniformly available across geography. Going forward, other emerging modes and technologies may similarly not be 
ubiquitously available. TNC availability has been most pronounced in the largest urban areas with early footholds on the west coast. Scooter and bike share options have been differentially embraced across geography and considerations such as climate and regulatory environments might influence the relatively availability of mobility as a service/automated vehicle options in the future. Ultimately, fully understanding travel behavior at the national level will require future data collection efforts to be sensitive during design such that sample weighting fully accounts for the availability of travel options as well as the host of sociodemographic, economic, and other characteristics that are understood to influence travel behavior. This is particularly true in situations where add-on samples produce very different sample rates across geography.

This observation is not intended to discredit all that can be gleaned from available data but it is shared as a caution to analysts. Similarly, with respect to public transportation, this phenomenon is not unique to the 2017 survey but is relevant to prior surveys as well.

The adequacy of the NHTS sample for analyzing public transit ridership information was explored in a FHWA NHTS report," Transit Trends Analysis", 2017 National Household Travel Survey, released in February 2019. This exploration grew out of initial concerns that the new survey results indicated that public transit mode share for all trip purposes increased from $2.0 \%$ in 2009 to $2.54 \%$ in 2016 , an increase of approximately $27 \%$ in mode share. This increase in mode share was curious in the context of the fact that actual transit ridership counts declined approximately $4 \%$ between the respective survey periods in spite of growing population and expanded service. Ridership has declined an additional approximate 4\% since the 2017 NHTS survey.

Table 2 shows a variety of characteristics of the 2017 NHTS transit sample. The sample was based on 5,603 respondents reporting transit trips with the actual transit trip count being 11,090 . For perspective the Middle Atlantic had 1732 respondents reporting a transit trip which constituted over $30 \%$ of transit using respondents. Based on national transit data which is attributed to the headquarter location of the operating agency, the Middle Atlantic constituted over $48 \%$ of U.S. transit ridership during the reference period. Middle Atlantic residents constituted $35.7 \%$ of the weighted respondents reporting transit trips. Interestingly, the South Atlantic, the largest region by population, but not a particularly strong transit ridership region, had 750 respondents and 1496 linked transit trips included in the NHTS sample but with weighting had a share of transit trips higher than their $10.7 \%$ share of U.S transit ridership. 
Table 2. The 2017 NHTS Sample

\begin{tabular}{|c|c|c|c|c|c|c|c|c|c|c|c|c|}
\hline $\begin{array}{l}\text { Census } \\
\text { Division }\end{array}$ & $\begin{array}{c}\text { Unlinked } \\
\text { NTD Trips, } \\
12 \text { Months } \\
\text { thru March } \\
2017\end{array}$ & $\begin{array}{c}\text { Percent } \\
\text { of U.S. } \\
\text { Total } \\
\text { Ridership }\end{array}$ & $\begin{array}{l}\text { Number of } \\
\text { Respondents } \\
\text { Reporting } \\
\text { Transit Trips }\end{array}$ & Percent & $\begin{array}{c}\text { Number of } \\
\text { Weighted } \\
\text { Respondents }\end{array}$ & Percent & $\begin{array}{l}\text { Number of } \\
\text { Unweighted } \\
\text { Transit } \\
\text { Trips } \\
\text { (Linked) }\end{array}$ & $\begin{array}{l}\text { Number of } \\
\text { Weighted } \\
\text { Transit } \\
\text { Trips } \\
\text { (Linked) }\end{array}$ & Percent & $\begin{array}{c}\text { ACS } \\
\text { Census } \\
\text { Population } \\
\text { share } \\
(2017)\end{array}$ & $\begin{array}{c}\text { Total } \\
\text { NHTS } \\
\text { Person } \\
\text { Trips } \\
\text { Sample } \\
\text { Size }\end{array}$ & $\begin{array}{c}\text { Total } \\
\text { NHTS } \\
\text { Person } \\
\text { Sample } \\
\text { Size }\end{array}$ \\
\hline U.S & 9956258875 & & 5603 & & 12980344 & & 11090 & 9444506728 & & & & \\
\hline New England & 489951066 & $4.9 \%$ & 122 & $2.2 \%$ & 784391 & $6.0 \%$ & 253 & 594386071 & $6.3 \%$ & $4.6 \%$ & $4.8 \%$ & $4.6 \%$ \\
\hline Middle Atlantic & 4806402739 & $48.3 \%$ & 1732 & $30.9 \%$ & 4634634 & $35.7 \%$ & 3492 & 3482002763 & $36.9 \%$ & $12.7 \%$ & $12.8 \%$ & $13.0 \%$ \\
\hline East North Central & 908308872 & $9.1 \%$ & 493 & $8.8 \%$ & 1731064 & $13.3 \%$ & 967 & 1284442963 & $13.6 \%$ & $14.4 \%$ & $14.9 \%$ & $14.6 \%$ \\
\hline West North Central & 204995761 & $2.1 \%$ & 95 & $1.7 \%$ & 372165 & $2.9 \%$ & 166 & 231513462 & $2.5 \%$ & $6.5 \%$ & $6.7 \%$ & $6.6 \%$ \\
\hline South Atlantic & 1069253043 & $10.7 \%$ & 750 & $13.4 \%$ & 1777320 & $13.7 \%$ & 1496 & 1277667195 & $13.5 \%$ & $19.9 \%$ & $19.3 \%$ & $19.7 \%$ \\
\hline East South Central & 50048021 & $0.5 \%$ & 20 & $0.4 \%$ & 199549 & $1.5 \%$ & 33 & 116871911 & $1.2 \%$ & $5.9 \%$ & $5.9 \%$ & $5.9 \%$ \\
\hline West South Central & 308834230 & $3.1 \%$ & 717 & $12.8 \%$ & 594252 & $4.6 \%$ & 1466 & 442495746 & $4.7 \%$ & $12.3 \%$ & $11.9 \%$ & $12.0 \%$ \\
\hline Mountain & 346715298 & $3.5 \%$ & 118 & $2.1 \%$ & 557519 & $4.3 \%$ & 214 & 374875979 & $4.0 \%$ & $7.4 \%$ & $7.7 \%$ & $7.3 \%$ \\
\hline Pacific & 1771749845 & $17.8 \%$ & 1556 & $27.8 \%$ & 2329452 & $17.9 \%$ & 3003 & 1640250638 & $17.4 \%$ & $16.3 \%$ & $16.1 \%$ & $16.3 \%$ \\
\hline
\end{tabular}

The survey design and sampling plan was cognizant of the consequences of integrating add-on respondents into the total sample and chose to leverage this data to enrich the sample. However, a consequence is the risk that conditions beyond those reflected in the weighting strategies are sufficiently different across geographies to result in different quality and availability of various travel options or other conditions (such as climate, exposure to crime, or culture, for example) that can explain behavior differences.

The consequence of this phenomenon coupled with the prospects of response bias result in the need for a great deal of discernment when interpreting results from the $2017 \mathrm{NHTS}$ for smaller sectors of travel such as public transportation. Accordingly, throughout the remainder of this report we would urge caution in interpretation of differences between the 2017 results and prior year data. 
Table 3. Transit Mode Share Comparisons

\begin{tabular}{|l|r|}
\hline \multicolumn{2}{|c|}{ Transit Mode Share Comparisons } \\
\hline Transit Ridership Unlinked Trips, BTS data, April 2008 through March 2009 (millions) & 10,613 \\
\hline Transit Ridership Unlinked Trips, BTS data, April 2016 through March 2017 (millions) & 10,179 \\
\hline Estimated U.S. population (5 and older) in 2008-2009 (millions) & 283 \\
\hline Estimated U.S. population (5 and older) in 2016-2017 (millions) & 301 \\
\hline Estimated Person Trips in 2008-2009 (millions) & 392,023 \\
\hline Estimated Person Trips in 2016-2017 (millions) & 371,145 \\
\hline Estimated Transit Trips in 2008-2009 (millions) & 7,615 \\
\hline Estimated Transit Trips in 2016-2017 (millions) & 9,445 \\
\hline Sampled Transit Trips in 2008-2009 & 8,637 \\
\hline Sampled Transit Trips in 2016-2017 & 11,090 \\
\hline Persons reporting one or more transit trips 2008-2009 & 4,942 \\
\hline Persons reporting one or more transit trips 2016-2017 & 5,603 \\
\hline Average transit trips per respondent 2009 & 1.75 \\
\hline Average transit trips per respondent 2017 & 1.98 \\
\hline Estimated Transit Mode Share in 2008-2009 & $1.92 \%$ \\
\hline Estimated Transit Mode Share in 2016-2017 & $2.54 \%$ \\
\hline Estimated 2016-2017 Transit mode share had Trip Rate remained as in 2008-2009 & $2.03 \%$ \\
\hline
\end{tabular}

Table 3 includes data on transit use in 2009 compared to 2017. It is important to note that the sample of transit trips in 2017 was approximately 30\% larger than in 2009. It was also interesting to note that in both reporting periods the average number of transit trips for the travel survey day is less than two. This suggests a significant number of travelers made one-way trips on public transportation. It is also interesting to note that the overall decline in trip making may have played a factor in increasing transit mode share. What is unknown is whether or not persons using transit have a greater or lesser tendency to reduced trip making relative to the overall decline in per capita trip making. Specifically, are the types of trips made on transit less likely to be foregone or replaced with communications instead of travel?

Figure 1 compares the trend in sub mode split between bus and rail transit sub modes for the U.S. dating back to the 1995 NPTS survey compared to the same sub mode split calculated from National Transit Database (NTD) data. Some slight nuances of what constitutes each transit mode have changed over the years of the survey. For 2001, "Local public transit bus" and "commuter bus" were grouped for the bus mode and "Amtrak/intercity train", "Commuter train", "Subway/elevated rail", "Streetcar/trolley" were grouped for rail. For 2009, "local public bus" and "commuter bus" were grouped for the bus mode and "Amtrak/intercity train", "Commuter train", "subway/elevated train", "Streetcar/trolley" were grouped for rail mode. For 2017, "public or commuter bus", "Paratransit/Dial a ride" were grouped for the bus mode, 
and "Amtrak/Commuter rail", "Subway/elevated/light rail/streetcar" were grouped for rail. These totals were used to calculated percentages of the mode share. Both datasets show a decreasing trend in bus ridership over time, accompanied by increased rail shares.

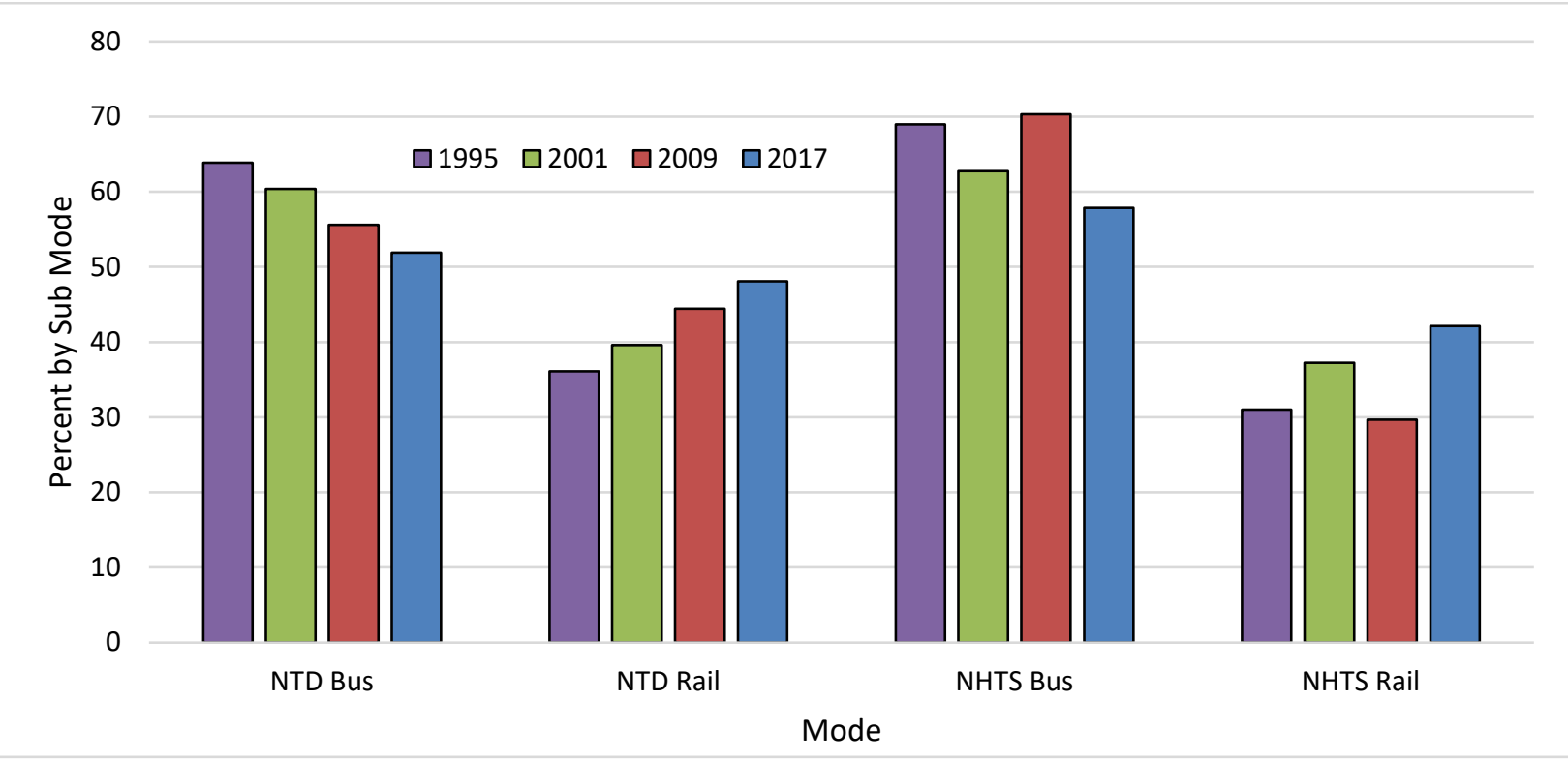

Figure 1. Trend in Transit Sub Mode Share

\section{Who's Using Public Transit -The Demographic Profile of Transit Users}

One of the areas of interest for public transportation is understanding the market segments and the extent to which various markets are using public transportation. Public transportation has always been critical to those individuals who do not have automobiles available or are unlicensed to drive but as this segment of the population has declined over time the public transportation industry has sought to attract other travelers who for various reasons find public transportation meeting their needs. Specifically, public transportation has increasingly targeted areas with high cost parking, high demand special events or other characteristics where public transportation might be competitive. For instance, numerous communities have added express or guideway services connecting airports to downtown and other destinations. Convention centers, arenas, major retail centers, intermodal transportation centers and universities are among the activity centers that transit agencies have sought to serve in addition to the central business districts that have long been a dominant destination for transit travelers. The desire to expand the role that public transportation can play in meeting mobility needs motivates a desire to become competitive in meeting travel needs for a broader demographic market. 


\section{Public Transit and Auto Availability}

Among the metrics that give insight into the ability of public transportation to capture additional markets are the distribution of auto ownership characteristics and income levels amongst public transportation users. Figure 2 shows the historic trend in the share of transit users by household vehicle ownership count. As the data indicate, the zero-vehicle household component of the market has been almost half of all riders over the past three survey cycles. The share of travel by this segment has remained high but has declined modestly with the most recent survey. The most recent survey also shows a slight increase in the share of transit trips that are were made by members of households that have three or more

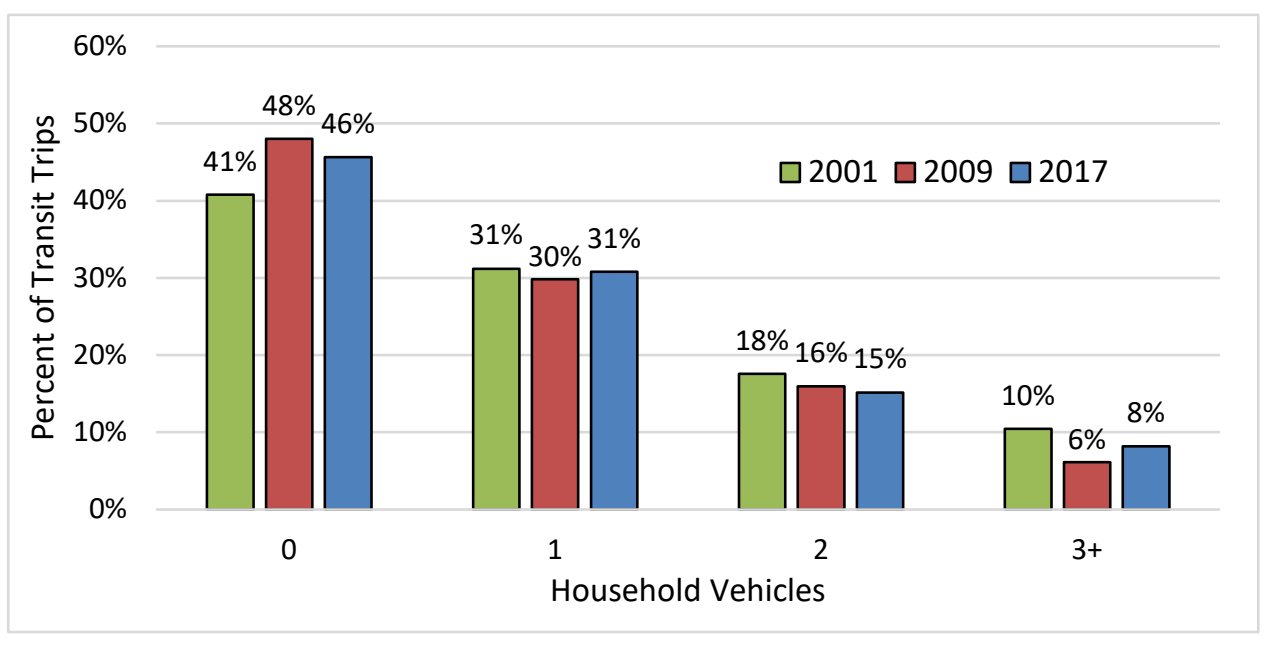

Figure 2. Share of Transit Trips by Household Vehicle Availability vehicles.

This measure, of course, does not tell the whole story as some share of the zero-vehicle households have chosen to be without vehicles because other travel options including transit are available. In the most recent NHTS, $25.1 \%$ of all transit trips taken by residents of zerovehicle households were from those whose income was in the top three income quintiles suggesting that financial constraints were not a factor in their decision to not have household vehicles, as shown in Table 4. In prior surveys, these shares were $20.5 \%$ and $17.8 \%$ in 2009 and 2001 respectively. The 2017 data showed meaningful larger shares in the top two quintiles.

Table 4. Zero-Vehicle Household Transit Use by Income Quintile (Percent of all Transit Trips)

\begin{tabular}{|c|c|c|c|c|c|}
\hline $\begin{array}{c}\text { Approximate } \\
\text { Quintiles -> }\end{array}$ & $\begin{array}{c}\text { First Income } \\
\text { Quintile }\end{array}$ & $\begin{array}{c}\text { Second } \\
\text { Income } \\
\text { Quintile }\end{array}$ & $\begin{array}{c}\text { Third Income } \\
\text { Quintile }\end{array}$ & $\begin{array}{c}\text { Forth Income } \\
\text { Quintile }\end{array}$ & $\begin{array}{c}\text { Fifth Income } \\
\text { Quintile }\end{array}$ \\
\hline \multirow{2}{*}{2017} & $<\$ 25,000$ & $\$ 25,000-\$ 49,000$ & $\$ 50,000-\$ 74,999$ & $\$ 75,000-\$ 124,999$ & $>\$ 125,000$ \\
\cline { 2 - 6 } & $59.1 \%$ & $15.8 \%$ & $7.7 \%$ & $10.0 \%$ & $7.4 \%$ \\
\hline \multirow{2}{*}{2009} & $<\$ 20,000$ & $\$ 20,000-\$ 39,999$ & $\$ 40,000-\$ 64,999$ & $\$ 65,000-\$ 99,999$ & $>\$ 100,000$ \\
\cline { 2 - 6 } & $56.7 \%$ & $22.9 \%$ & $8.4 \%$ & $7.4 \%$ & $4.7 \%$ \\
\hline \multirow{2}{*}{2001} & $<\$ 25,000$ & $\$ 25,000-\$ 39,999$ & $\$ 40,000-\$ 54,999$ & $\$ 55,000-\$ 79,999$ & $>\$ 80,000$ \\
\cline { 2 - 6 } & $61.4 \%$ & $20.9 \%$ & $7.1 \%$ & $4.4 \%$ & $6.3 \%$ \\
\hline
\end{tabular}


These data provide some credence to the prospect that a growing share of zero-vehicle households that make transit trips might have adequate resources to own vehicles but may have chosen to forgo vehicle ownership. While it is challenging working with income quintiles due to the income bracket categories used for survey respondents, which require approximation of quintiles, this income distribution approximation strategy provides insight on transit use as a function of household incomes. The 2017 data suggests a continued high dependence on low income, zero-vehicle household but also indicates growth in ridership provided by higher income zero-vehicle household residents.

Previous sections discuss the relationship between vehicle availability and transit ridership, with the share of transit riders decreasing as the number of household vehicles available increases (Figure 2). Another consideration that effects public transit ridership propensity is the relationship between the number of workers and the number of vehicles available. The relationship between vehicle ownership, household income, and worker status are not unilateral, and are correlated to each other, meaning each of these characteristics contain unobserved heterogeneity.

Figure 3 through Figure 5 show how the share of transit use varies by the relationship between vehicles available and workers within the household. Zero vehicle households with at least one worker account for the largest share of public transit trips in 2009 (32.5\%) and in 2017 (27.4\%), followed by zero vehicle households with no workers at $15.6 \%$ and $18.2 \%$ in 2009 and 2017 , respectively.

Households that have less vehicles than workers generally require at least one worker to use a non-drive alone commute mode. In 2009, $16.7 \%$ of all transit trips were of household members that were vehicle deprived. In 2017 that share increased to 17.9\%. These workers are more likely to be transit dependent riders, in general. However, choice riders account for a significant share of transit trips. Choice riders are defined as members of households that have an equal number of workers and vehicles, or a vehicle surplus. The share of theoretical choice riders was $35 \%$ in 2009 , and $36.4 \%$ in 2017.

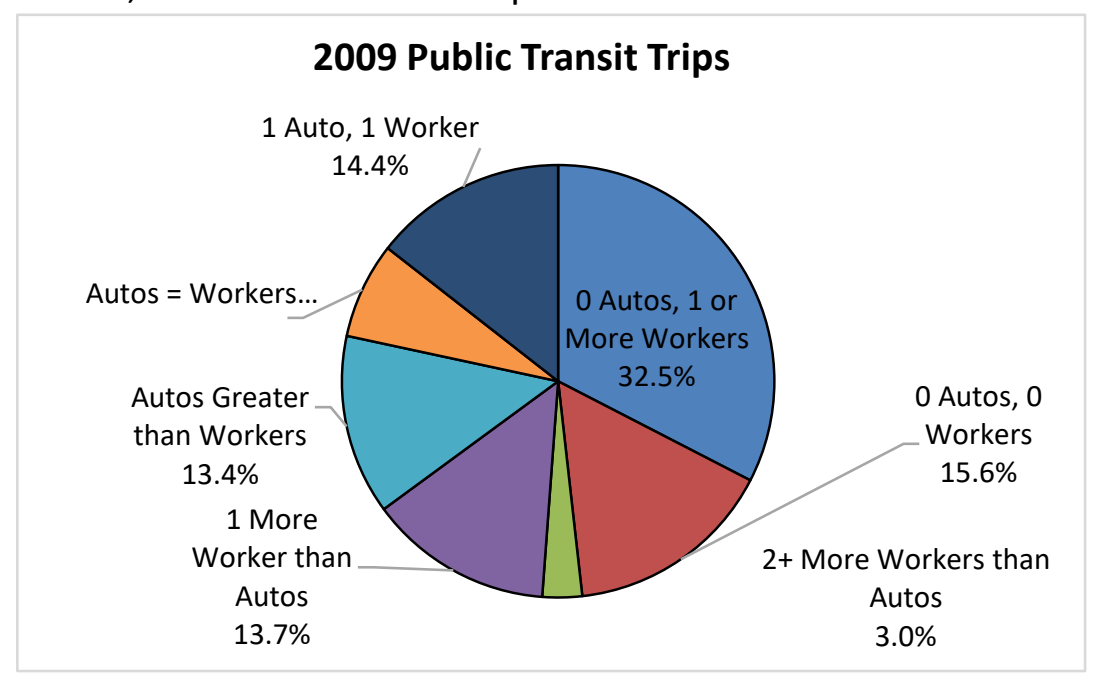

Figure 3. Public Transit Trip Share by Worker and Vehicle Availability, 2009 
Another way to look at the correlation between transit trips and how transit ridership is effected by the relationship between workers and vehicles available is to consider the share of total trips that are taken via transit by each worker vehicle configuration, as displayed in Figure 5.

The most notable trend shown in Figure 5 is the increased share of each segment in 2017, when compared to the 2009 survey data, which is expected due to the increased share in transit usage that was mentioned previously. Transit accounts for $25.3 \%$ of trips taken by members of households that have no vehicles available and at least one-worker. While $19.9 \%$ of trips taken by members of

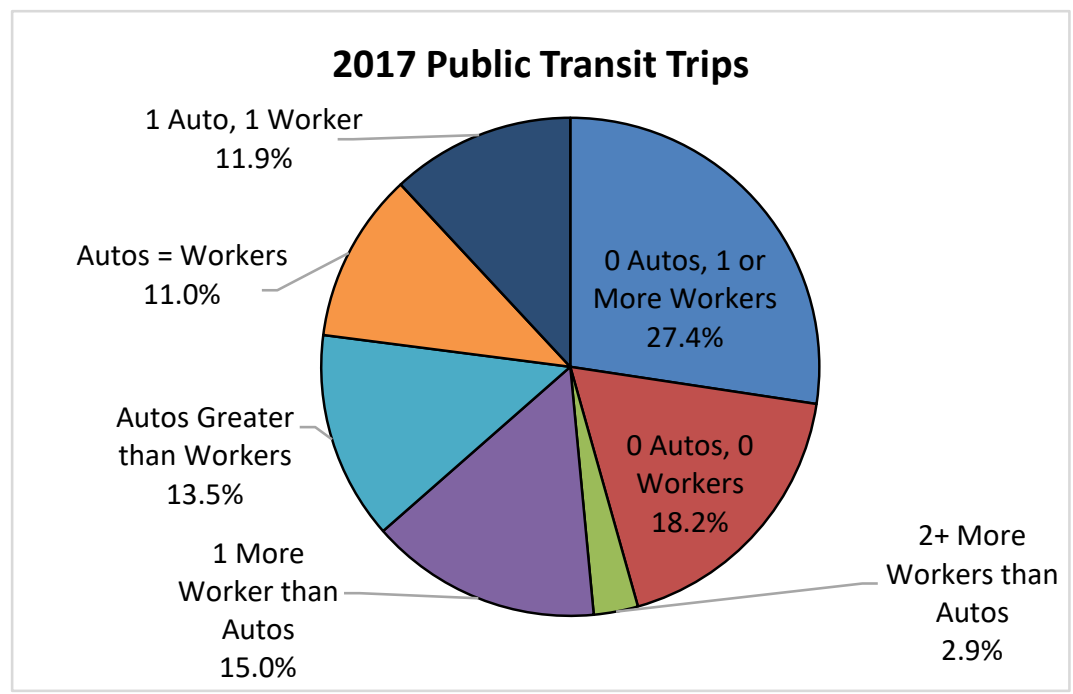

Figure 4. Public Transit Trip Share by Worker and Vehicle Availability, 2017 households with no workers and no vehicles available are on transit. As auto availability increases, the transit share of total trips decreases, regardless of the number of workers in the household. However, the households with more workers than vehicles consistently account for higher transit mode shares than their counterparts that have an equal number of workers and vehicles. Households with a vehicle surplus, or more vehicles than workers, have the smallest transit mode shares. The autos equal to workers category does not include one auto with oneworker households.

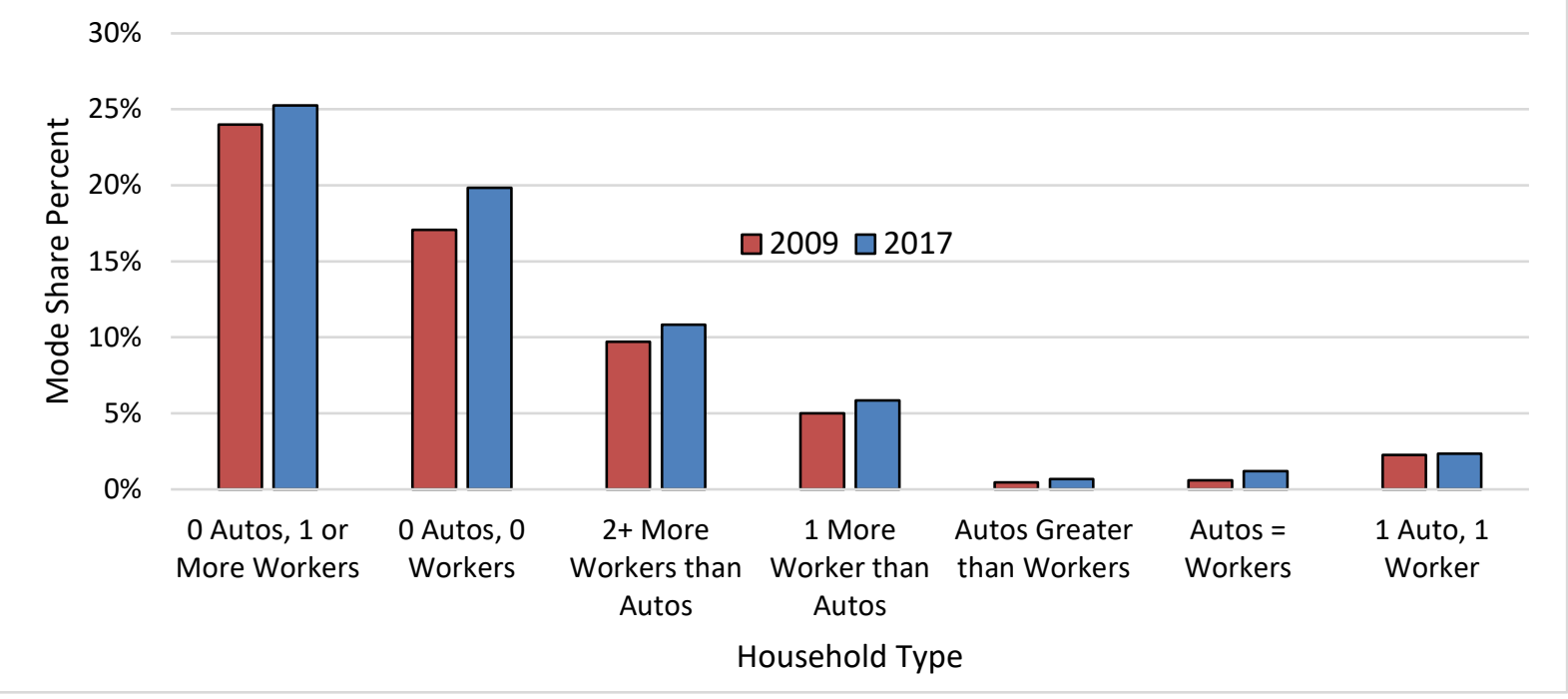

Figure 5. Transit Share of Total Trips by Worker Auto Availability Relationship 
This data reaffirms that vehicle ownership and worker status both have significant impacts on a person's propensity to use public transit. Households with no vehicles available consistently account for a larger transit mode share, regardless of the presence of workers in the household. Households with equal numbers of workers and vehicles consistently take less than $2.5 \%$ of all their trips on public transit. Additionally, as vehicle availability exceeds the number of workers in the household, the transit mode share decreases to less than $1 \%$ of all trips.

Perhaps the most powerful testimony to the importance of vehicle availability is shown by looking at the per capita annual trips by transit as a function of the household vehicle availability. Figure 6 presents that data for 2009 and 2017 NHTS data.

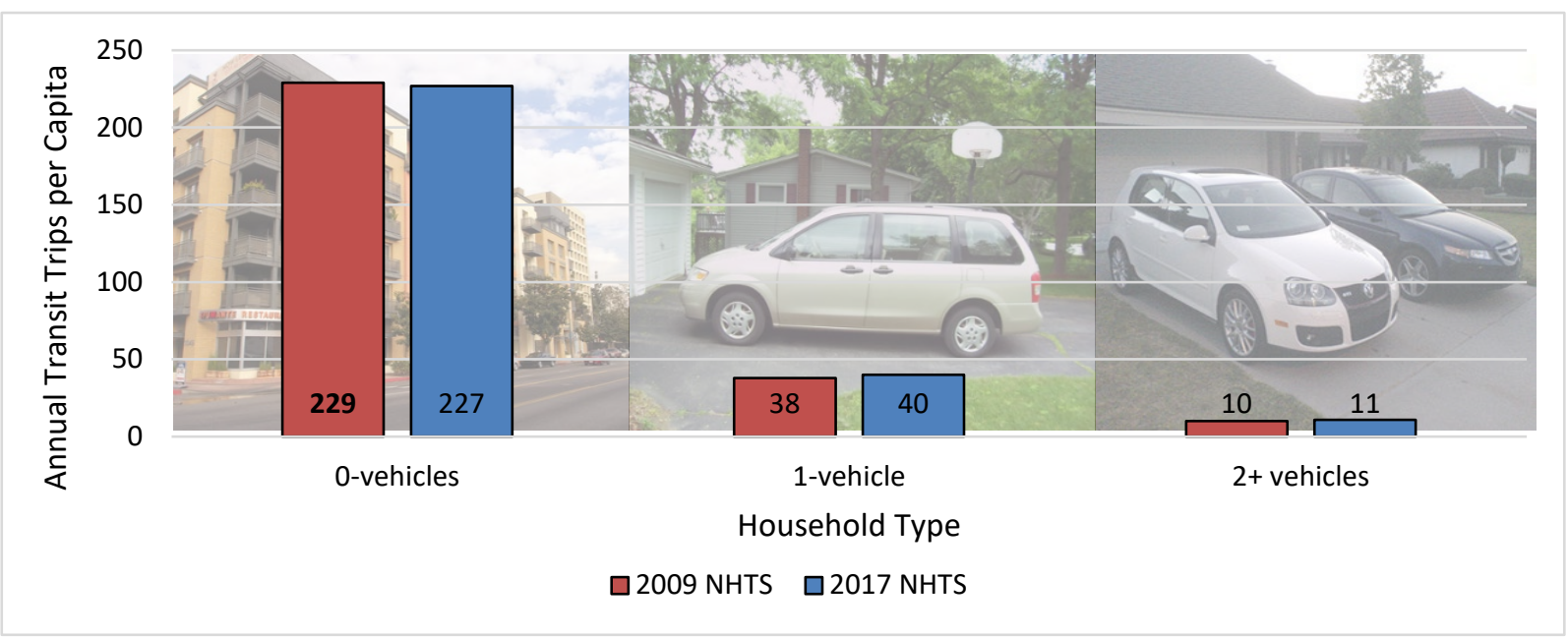

Figure 6. Per Capita Annual Transit Trips by Household Vehicle Availability

The dramatic decline in transit trip making as a function of household vehicle availability has tremendous explanatory power in understanding transit use. Going from zero vehicles to one vehicle per household results in an over $80 \%$ decline in per capita transit trip making. Going from one vehicle to two vehicles results in an additional more than $70 \%$ decline in transit trip making. While the significance of these changes has moderated a tiny amount between 2009 and 2017 , the role auto availability remains a tremendous explanatory factor in transit use at the national level.

\section{Public Transportation and Income}

A second element that adds insight with respect to the public transportation market, is the income distribution of transit travelers. The ability to attract higher income individuals to public transportation indicates that the services are sufficiently attractive to appeal to individuals who are likely to have other choices for travel. Growth in these market segments suggests an opportunity for continued expansion of public transportation ridership and provides an opportunity for these market segments to garner more of the direct benefits of public 
transportation. These market segments are often called upon to shoulder the majority of costs through property, sales, and income tax revenue streams that are traditionally relied upon to support local expenditures for public transportation.

Overall income distribution of transit riders can be extracted from the NHTS data set. It is most useful to express transit use in terms of mode share, which normalizes for differences in income bracket size and household counts. Figure 7 provides that data.

As the data indicate, there has been meaningful growth in the share of transit riders who come from higher income households. This suggests that this population group is increasingly benefiting from transit services. This may include white-collar central business district employees but also individuals using services targeting airports and special attractions as well as perhaps the growing number of middle and higher income central business district residents filling the growing number of high rise condo and apartment complexes in downtowns.

One might note that cost-of-living disparities are so significant across geography that a fuller assessment of behavior differences by income category might benefit from adjustments for cost-of-living differences across geography - particularly as there are different sample rates in different geographies.

The data indicates that travelers from higher income households comprise a larger share of travelers on rail modes. This is indicative of numerous factors including the prevalence of higher incomes in some of the larger Metropolitan areas that provide rail services and reflects the fact that these services typically offer higher speed travel and often cater to destinations such as central business districts and airports that are frequent destinations for higher income individuals. 


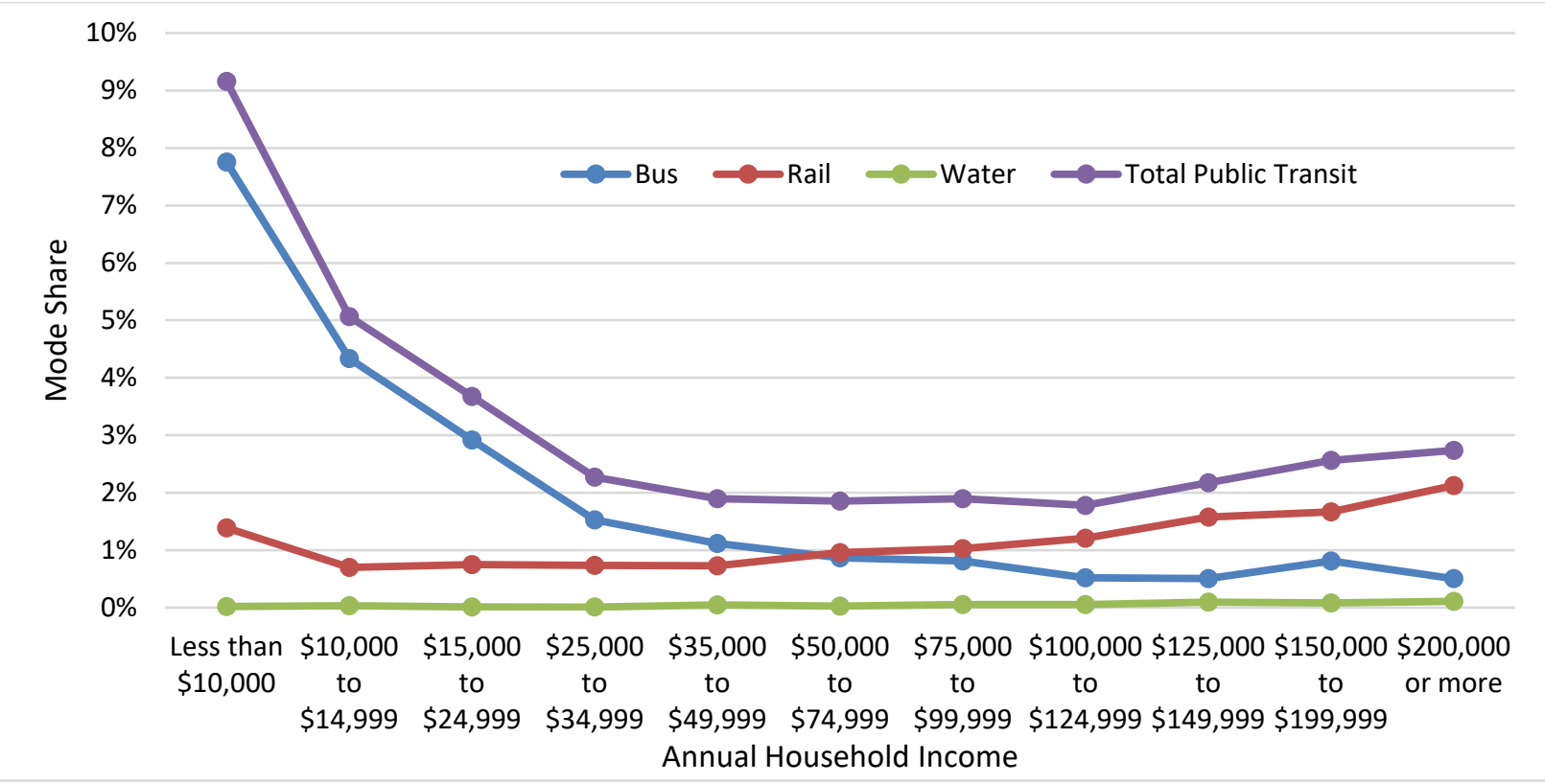

Figure 7. Commute Mode Share by Income, 2017

Delving further into the transit sub mode split by income quintiles, Figure 8 displays the trend in bus versus rail transit trip shares over the past three NHTS surveys. The overall trend in the sub mode shares has remained relatively similar over the survey years, with rail consistently accounting for less than $25 \%$ of all lowest income quintile population transit trips, and at least $60 \%$ of all the highest income quintile population transit trips. As of the most recent survey, $73.4 \%$ of all people in the highest quintile that took public transit used a rail mode while $26.6 \%$ took a transit bus on their travel day.

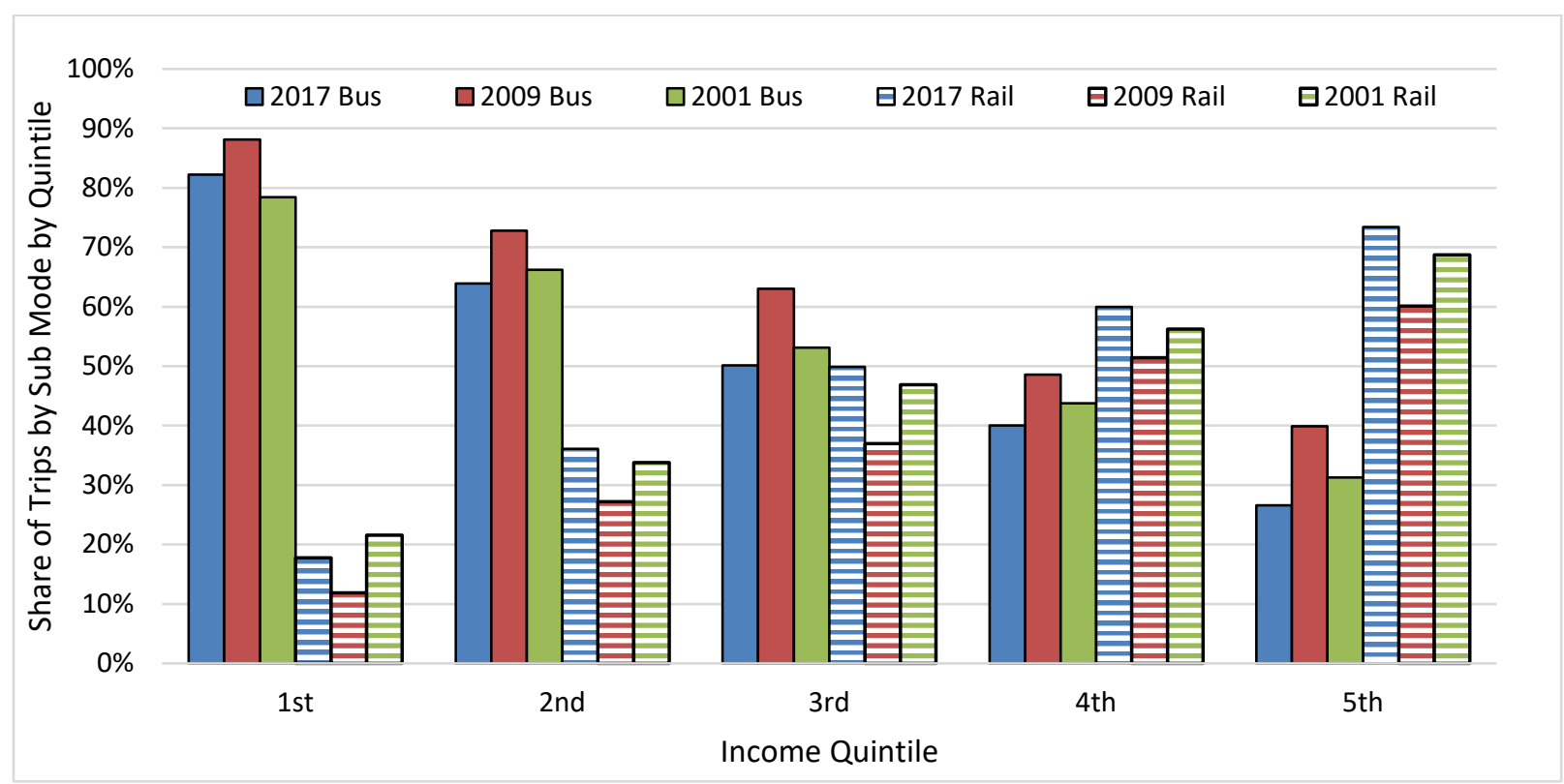

Figure 8. Transit User Sub Mode Split by Income Quintiles and Survey Year 
Figure 9 shows annual trip data in billions. This count data confirms the income distribution trends with transit use being most concentrated in the lower and higher income quintiles.

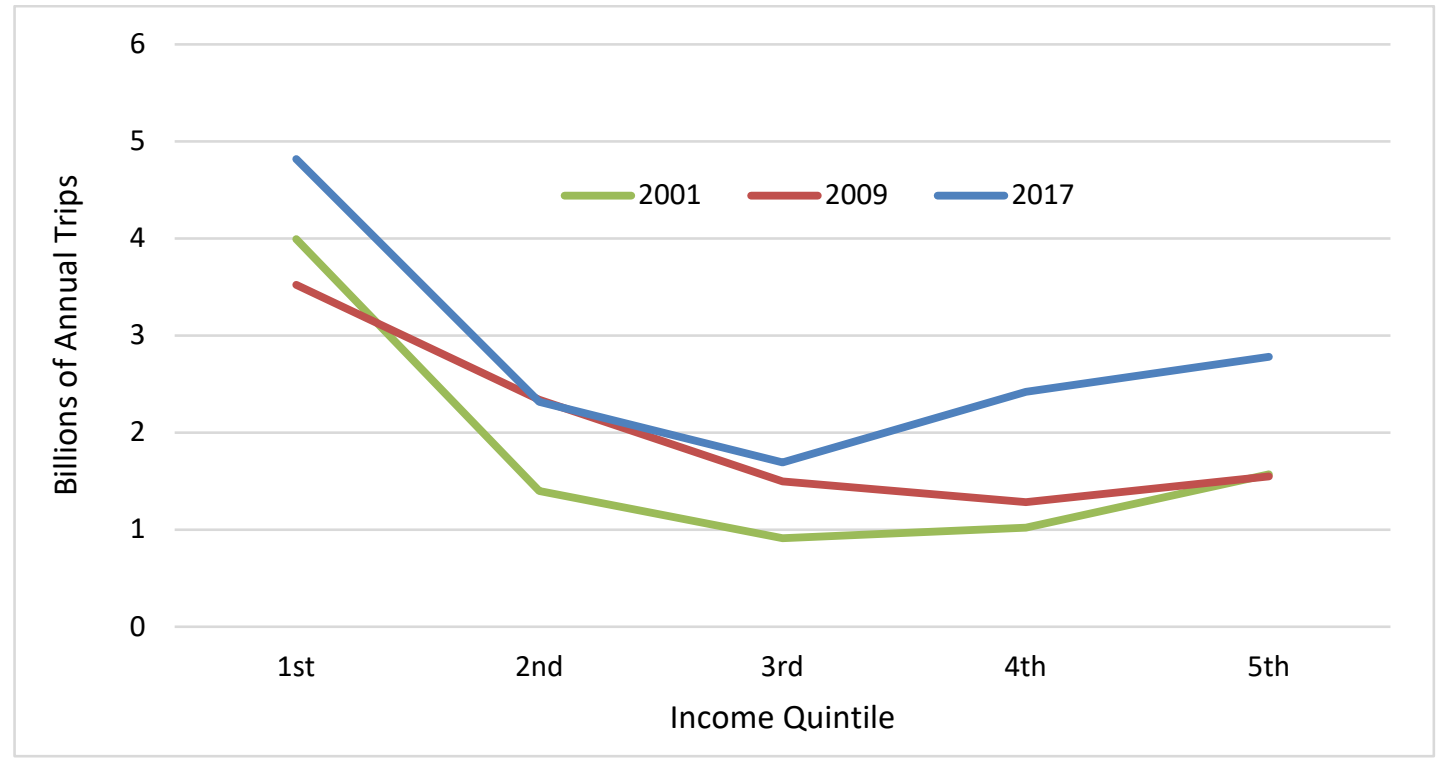

Figure 9. NHTS Transit Trips by Income Quintile

To validate the NHTS data trends, the ACS data on commuting was also reviewed to explore the income distribution of commuters with another data source. This analysis, presented in Figure 10 , uses $\$ 10,000$ income brackets for household income.

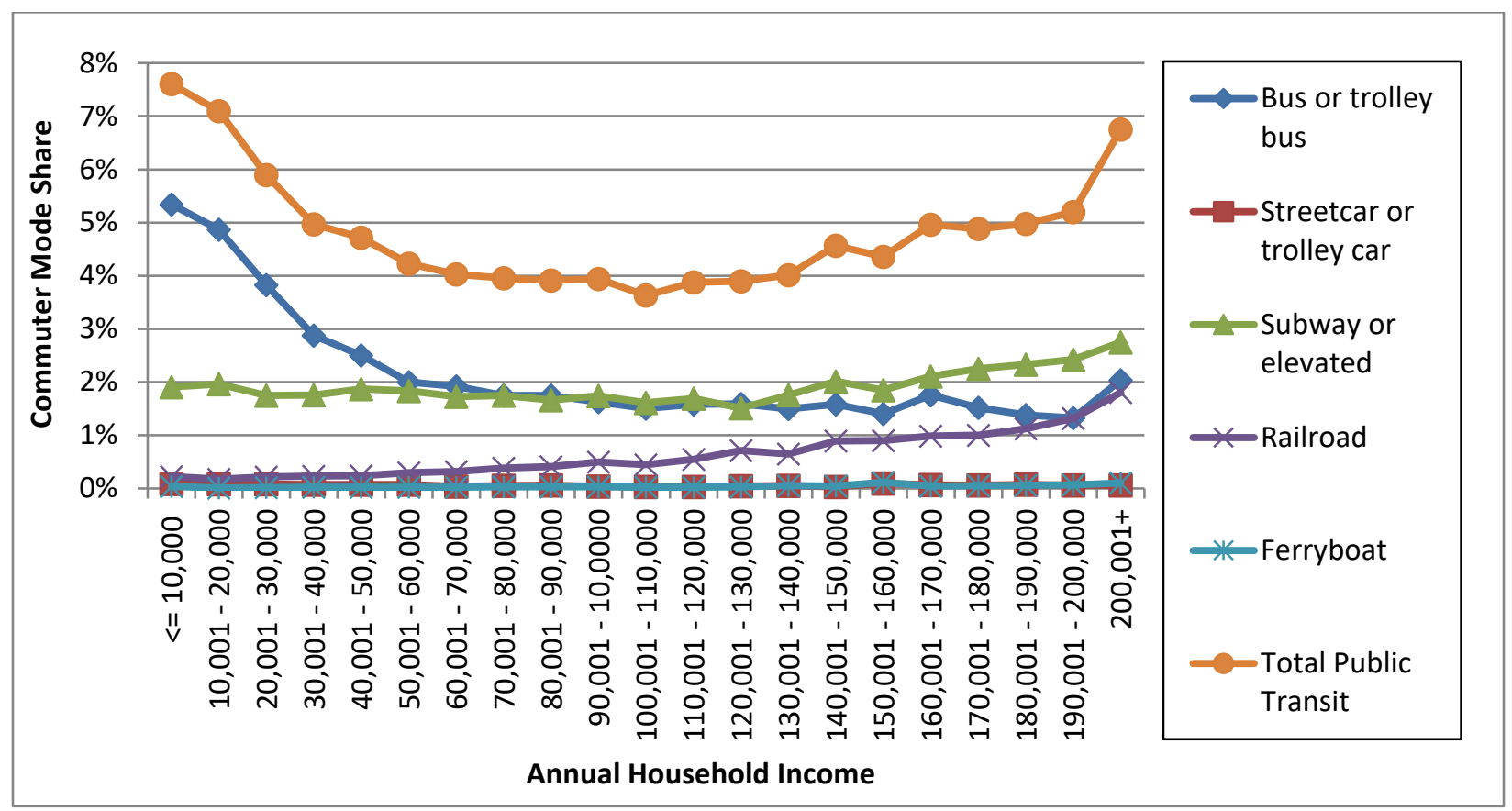

Figure 10. 2017 ACS Commuting Mode Share by Income and Transit Sub Mode 
While not directly comparable, this data reaffirms the general trends with higher use of subway or elevated rail and railroad in the higher income categories. Even bus use ticked up at the highest income levels but remained well below mode share numbers for low-income bus users. While not apparent at the graph scale, ferry use also trended up with income and streetcar was somewhat bipolar with higher use by low and high-income groups and lower use by middleincome categories.

The income distribution and its trend have significant implications with respect to service planning, marketing, pricing, and funding public transportation. This income profile does not match common perceptions of public transportation users across the country. Perceptions may not have kept up with both actual trends and the potential variation in distributions of income of travelers across markets and metropolitan areas. Clearly, at least in some significantly sized markets, public transportation is being used by residents of higher income households. This is certainly consistent with the presence of strong public transit markets in communities like New York, Chicago, Boston, Philadelphia, Seattle, and others where strong central business districts rich in well-paying white-collar jobs attract public transit travelers. In these locations the zerovehicle households may not be as significantly correlated with low income as is generally the case. Many of the new and capital-intensive transit investments either cater to destinations that have high use by higher income individuals or, in some cases, contribute to gentrification where low income residents get priced out of locations with good access to higher quality transit modes and services.

One might note that if the analysis were expanded to transit passenger miles of travel by income versus trips, the tendency toward increased use by higher income households would be even more pronounced as trip length on subway and commuter rail modes are significantly longer than for bus trips. Not accounting for potential variation in sub mode trip length as a function of income level, commuter rail trips averaged 24.6 miles in 2017, heavy rail 4.6 miles, light rail 5.2 miles, and ferry 6.0 miles, whereas bus trips averaged 4.2 miles according to the American Public Transit Association Fact Book ${ }^{3}$.

\section{Public Transportation and Trip Purpose}

Trip purpose is one factor that plays a significant role in mode choice decisions, and as such, it is important to consider how transit ridership varies across trip purposes. As shown in Figure 11, transit was the mode of choice for $3.7 \%$ and 5.5\% of all work trips in 2009 and 2017, respectively. This indicates that the mode share of work-related transit trips increased 1.8

\footnotetext{
${ }^{3}$ https://www.apta.com/resources/statistics/Pages/transitstats.aspx, 2019 Appendix A tables in Excel format.
} 
percentage points between 2009 and 2017. The transit mode share of work trips is second only to medical/dental trips as of 2017.

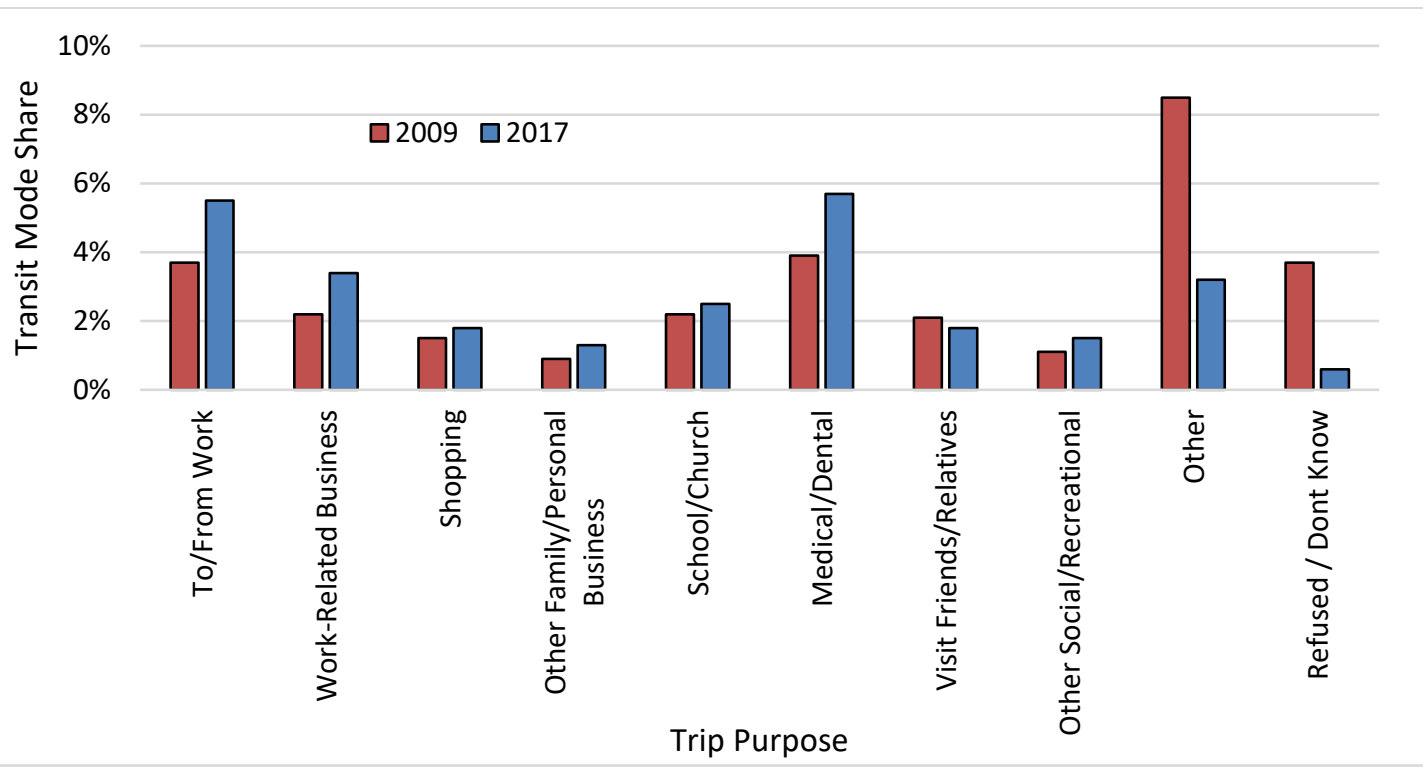

Figure 11. Trip Purpose Distribution Trend for Public Transit Trips

The variation in transit mode share by the number of household workers is presented in Figure 12. This transit share was calculated by dividing the number of transit trips taken by members of no-worker households, by total trips taken by members of no-worker households. From another perspective, trips to and from work account for the largest share of all transit trips, at $37.4 \%$ of all transit trips, as shown in Figure 13 . Shopping accounts for $13.1 \%$ of all transit trips, the next highest share of transit trips behind commuting.

As of the 2017 NHTS survey, trips to and from work account for $17.4 \%$ of all trips, with work-related business trips accounting for another $1.6 \%$ of total trips. Logically, it makes sense that workers would generally travel more than non-

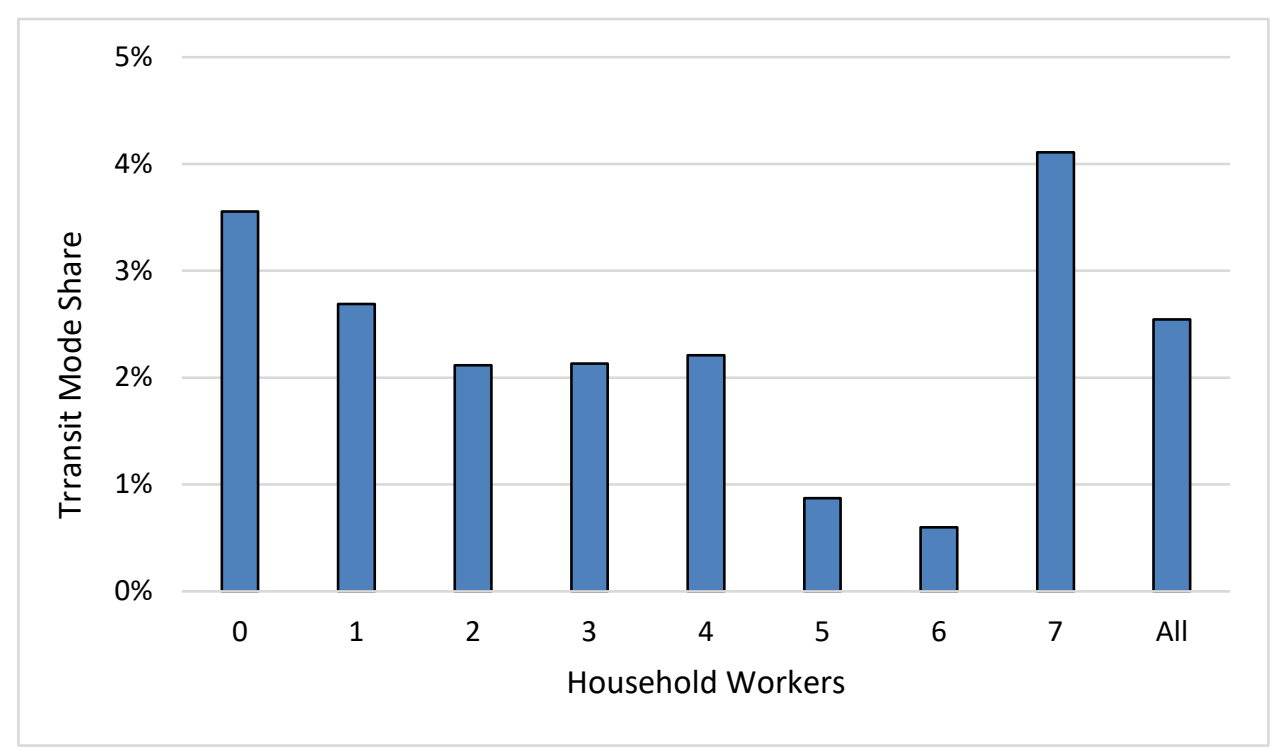

Figure 12. Transit Share of Total Trips by Household Worker Count, 2017 
workers, due to the necessity to travel to and from their place of employment. Considering commuting accounts for such a significant share of all trips, it is important to consider how the number of workers in a household effects the propensity to use transit. The analysis continued for each of the household worker counts in Figure 14.

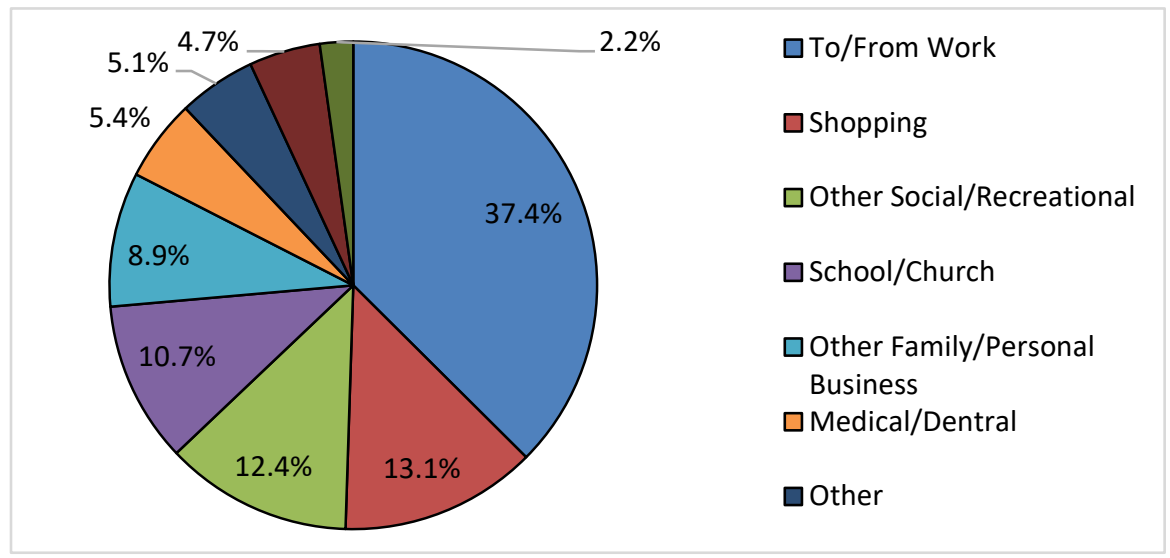

Figure 13. Transit Trips by Trip Purpose, 2017

\section{Public Transportation and Worker Status}

Worker status is another element that adds insight with respect to the public transportation market. Work trips account for a significant share of total transit trips, and account for the second highest mode share for all trip purposes. Therefore, another relationship to consider when exploring the NHTS for public transit observations is how the share of transit trips vary by the number of household workers. In other words, what share of total transit trips are taken by members of households with no workers compared to

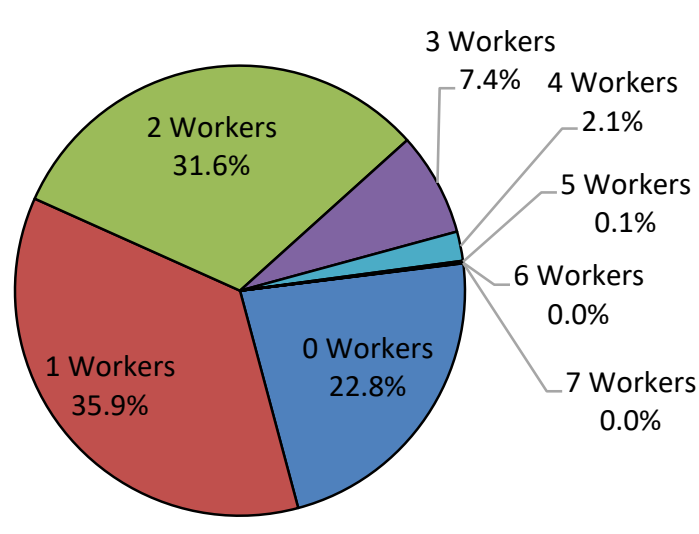

Figure 14. Share of Transit Trips by Household Worker Count, 2017 the share of transit trips that are taken by members of households with five workers. This relationship is displayed graphically in Figure 14. Members of one-worker households account for the largest share of total transit trips at $35.9 \%$, followed closely by two-worker households at $31.6 \%$, and no-worker households at $22.8 \%$. 


\section{Public Transportation and Home Ownership}

Members of renter occupied homes account for a disproportionate share of transit trips.

Typically, renter occupied homes account for about a third of all occupied homes, which is a trend that has remained mostly consistent over time, irrespective of the survey. Table 5 shows the comparison between the NHTS survey and the ACS survey for 2009 and 2017 survey years. While the share of renters only constitutes about one third of total occupied housing, renters account for more than four times the share of public transit trips than homeowners.

Table 5. Share of Owner vs. Renter Occupied Housing

\begin{tabular}{|l|c|c|c|c|}
\hline \multirow{2}{*}{ Owner Occupied } & \multicolumn{2}{|c|}{ ACS } & \multicolumn{2}{c|}{ NHTS } \\
\cline { 2 - 5 } & 2009 & 2017 & 2009 & 2017 \\
\hline Renter Occupied & $34.1 \%$ & $63.9 \%$ & $66.6 \%$ & $63.7 \%$ \\
\hline
\end{tabular}

The public transit mode share of total trips for renters has slightly increased 0.9 percentage points over the NHTS survey years from $4.3 \%$ in 1995 to $5.2 \%$ in 2017, as shown in Figure 15. During that same time, the public transit mode share of total trips made by occupants of owned homes increased from $0.9 \%$ to $1.3 \%$, an increase of only 0.4 percentage points.

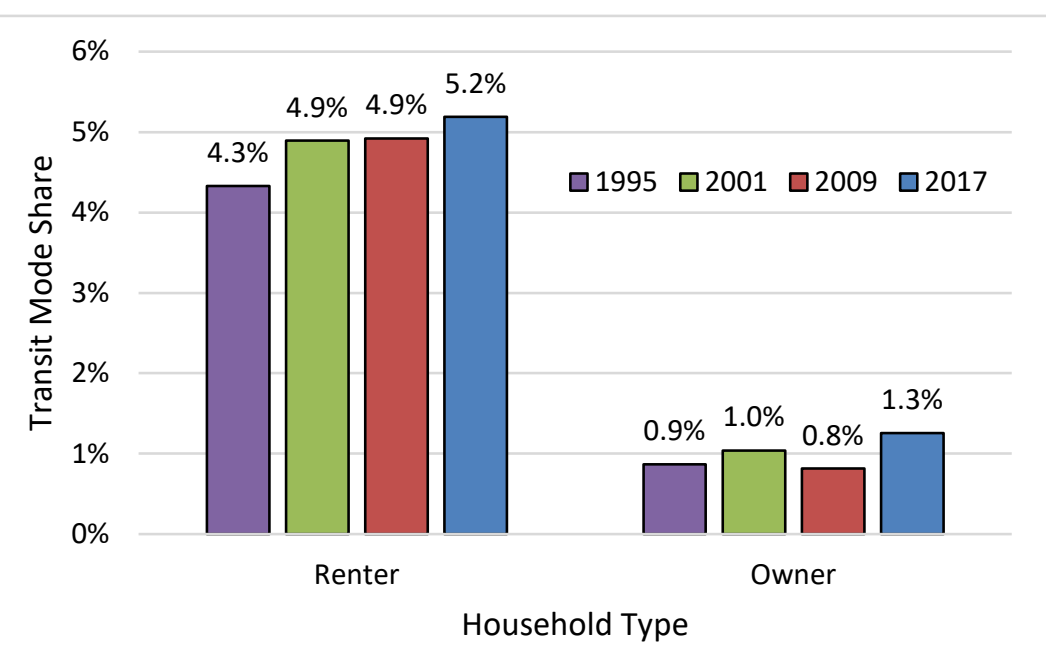

Figure 15. Public Transit Share of Trips by Home Ownership

The transit mode share of occupants of rented homes is four times that of the mode share of occupants of owned homes, which is disproportionate to the population relationship.

\section{Public Transportation and Gender}

As displayed in Figure 16, the public transit mode share does not vary much by gender, with males and females consistently within less than half a percentage point of mode share variance. Over the survey years, the differences between transit mode shares by gender have decreased, and as of 2017, males had a higher share of transit trips than females. In 2001, females used transit on $2.13 \%$ of all trips, while males used transit on $1.86 \%$ of their trips, a difference of 0.27 percentage points. In the 2009 survey, women still took transit at a slightly larger mode share 
than men, at $2.01 \%$ and $1.82 \%$ respectively. As of 2017 , the NHTS data reveals that males have a slightly larger transit mode share than women, at $2.57 \%$ and $2.52 \%$ respectively.

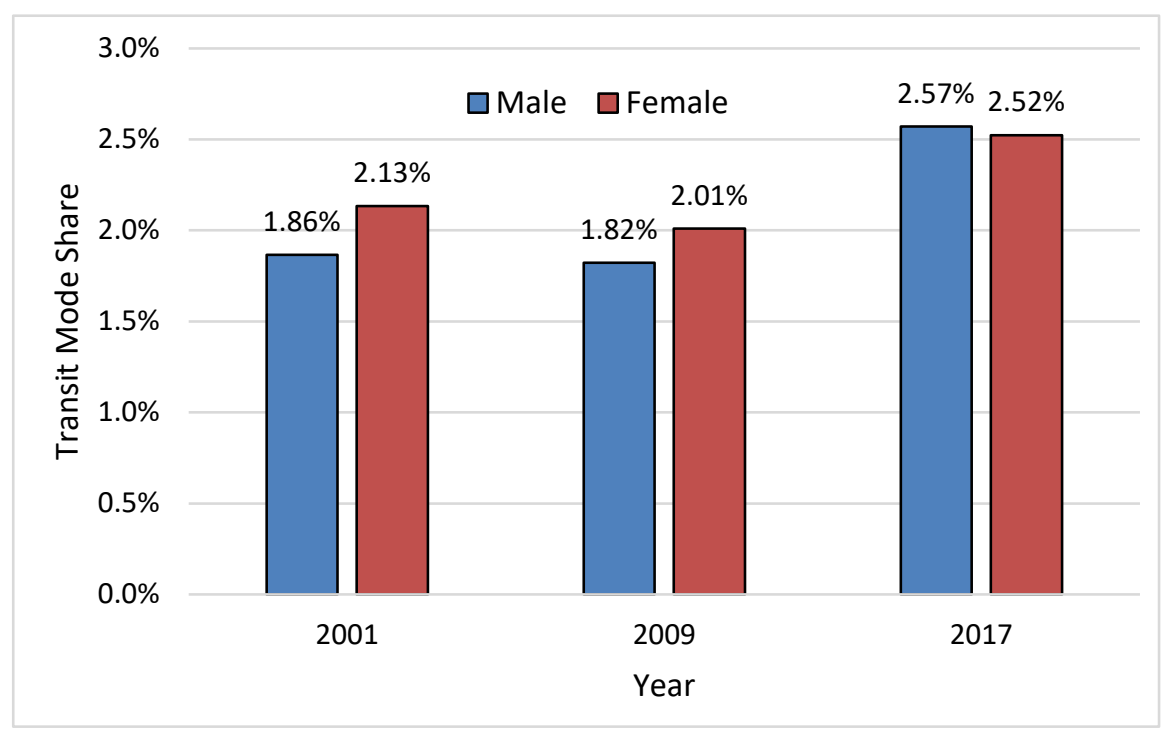

Figure 16. Public Transit Mode Share by Gender

\section{Public Transportation Travel by Age}

Figure 17 shows daily transit trips by age group. As expected, per capita trip rates peak at the 36-45 age group, and daily trip rates are generally higher in working age people than those who are younger or older. This daily per capita trip rate is especially influential when the transit mode share is considered simultaneously. Figure 18 displays the share of total trips that are made on public transit by age group, which peaks at the 16-25 age bracket. Daily per capita trips increase through the 36-45 age group, while the share of transit trips increases only through the $16-25$ age group.

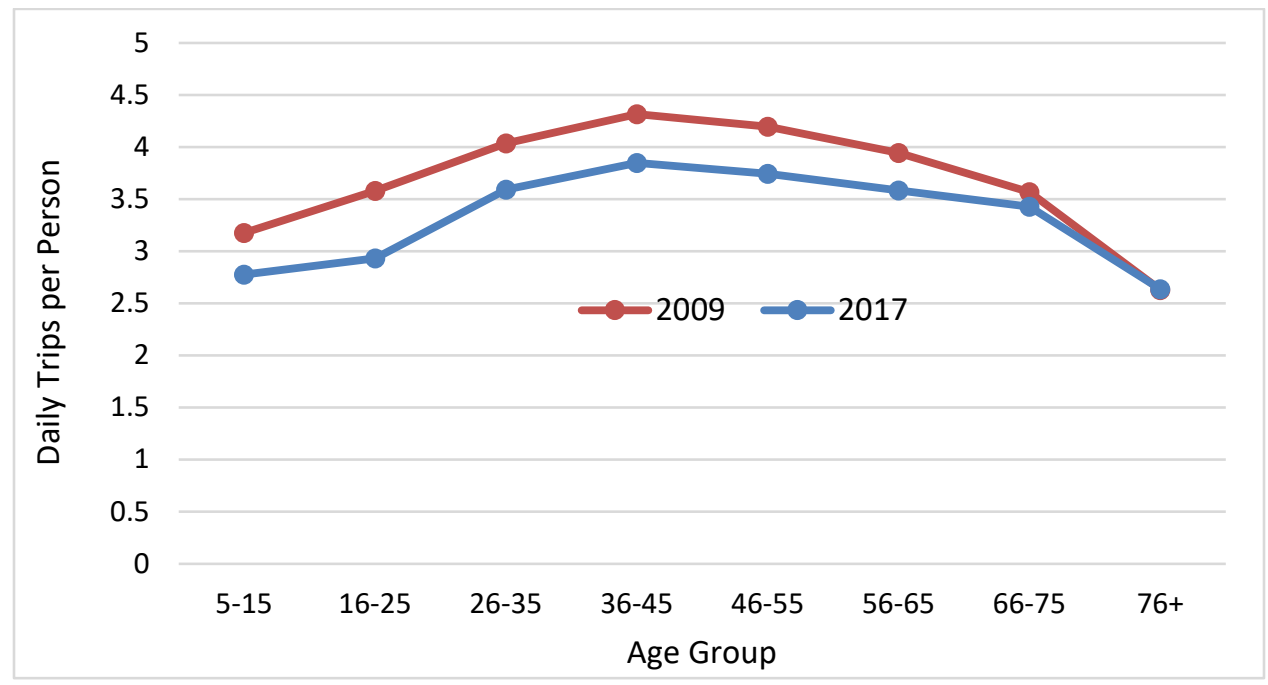

Figure 17. Daily Trips per Person 


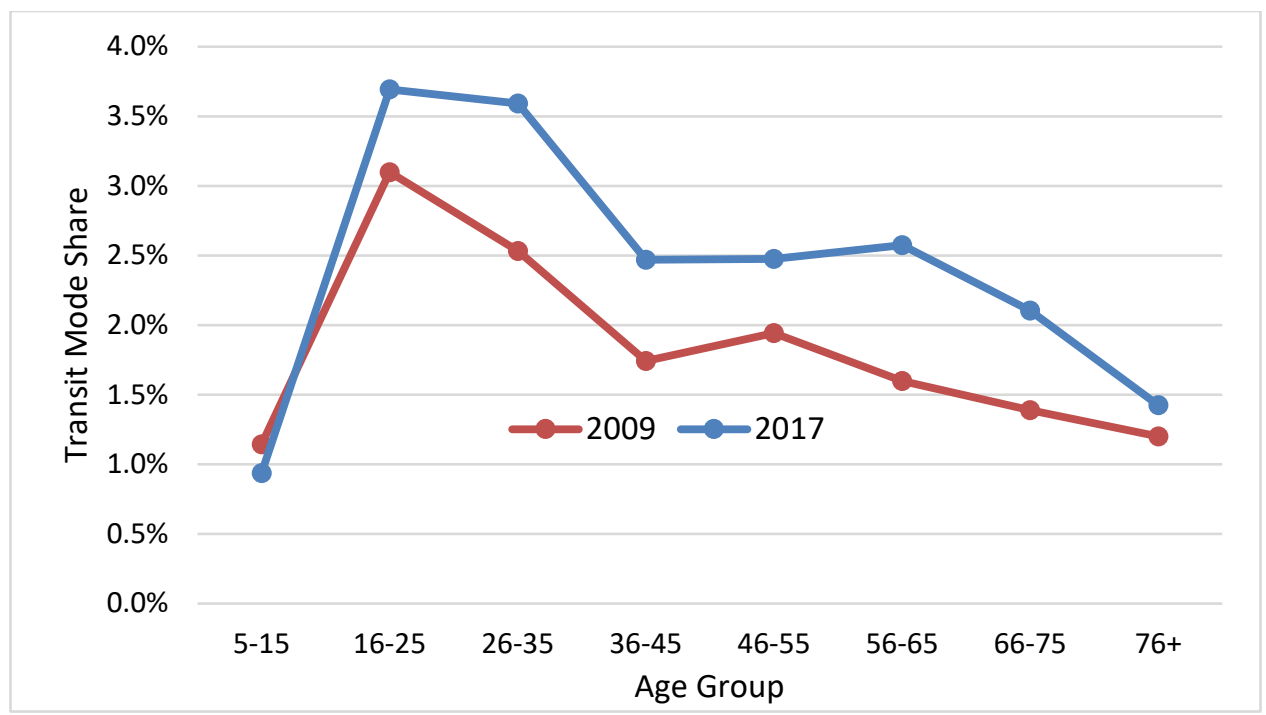

Figure 18. Transit Mode Share by Age

Taking a slightly different perspective, Figure 19 compares the share of transit trips by the age group of the person traveling for 2009 and 2017 survey years. While the trends has remained relatively consistent over the years, the share of transit trips taken by older populations is increasing. It is important to note that the size and share of this cohort is also increasing. Between 2009 and 2017 a smaller share of transit trips were made by persons 5-25 years old while a larger share of transit trips were taken by those aged 26 and above. This trend has led to an increase in the average age of transit trips. Figure 20 displays the same data, but only focusing on the transit trip shares by age group for the most recent survey year, 2017. When comparing 20-year increments

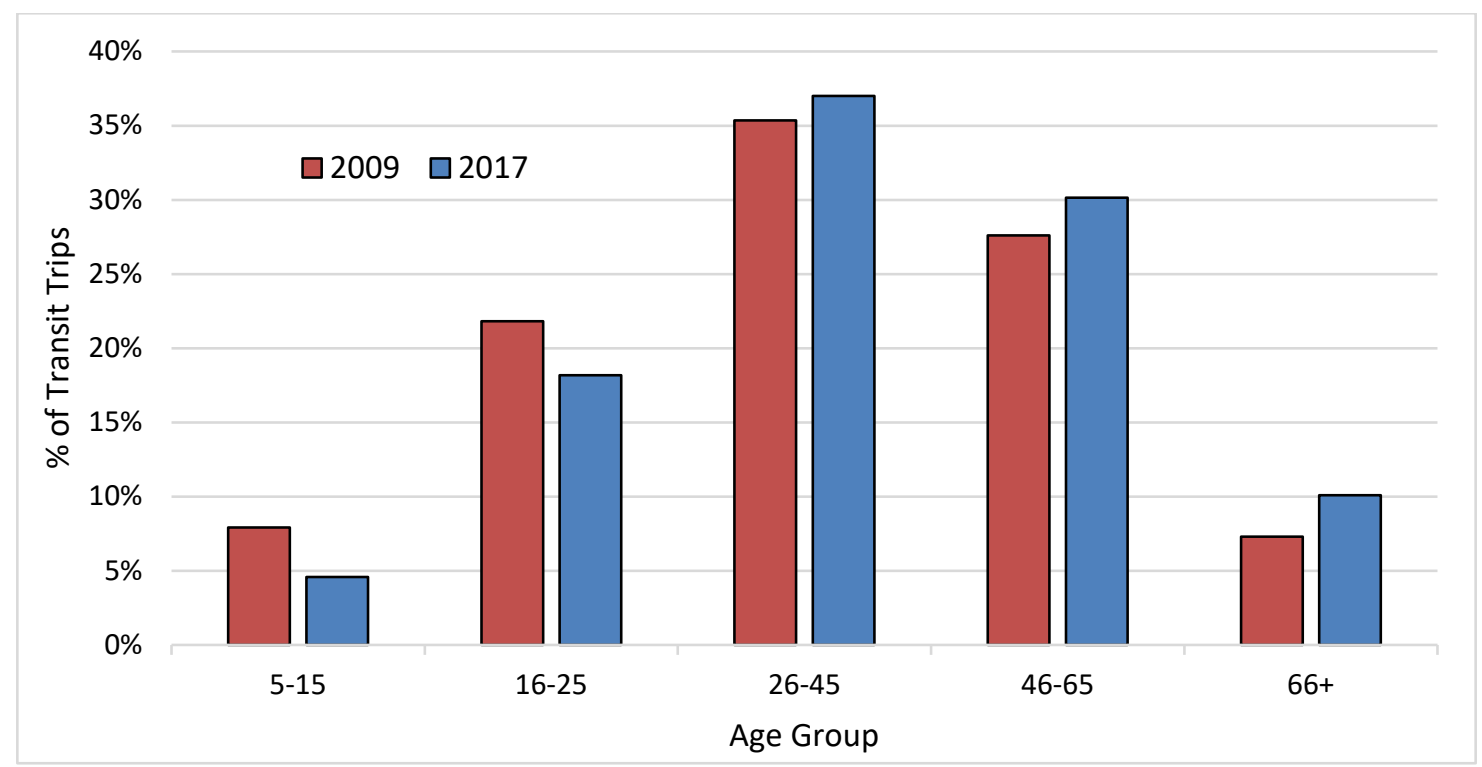

Figure 19. Share of Transit Trips by Age Group 


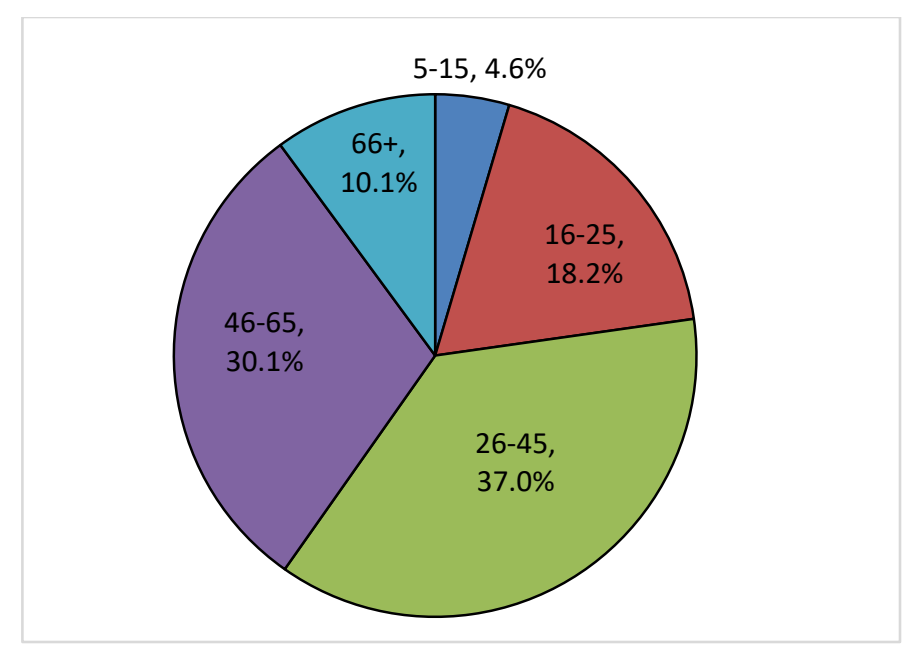

Figure 20. Share of Transit Trips by Age Group, 2017

Table 6 shows that the average age of a transit user is increasing over the survey years, which at least partially reflects the aging population. From 2009 when the average age of a transit user was 34.2 years old, the average age of a transit user has increased $20.5 \%$ to 41.2 years old. This again has significance when you consider how the daily trip rates decrease as age increases.

Table 6. Average Age of Transit Trips

\begin{tabular}{|l|c|c|c|}
\hline & $\mathbf{2 0 0 1}$ & $\mathbf{2 0 0 9}$ & $\mathbf{2 0 1 7}$ \\
\hline Average Age & 34.2 & 38.4 & 41.2 \\
\hline
\end{tabular}

Public transit mode share rates and person trip rates vary by age group, with peak daily trips occurring at the 36-45 age range, and peak transit mode share at the 16-25 age range. As the population ages, this relationship should be explored in more depth.

\section{Public Transportation Race/Ethnicity Distribution}

Figure 21 presents the major race and ethnicity classifications. Propensity to use public transit varies by race/ethnicity, with non-Hispanic Whites accounting for the largest share of public transit trips in 2017 at $39.9 \%$ of all transit trips, as shown in Figure 21. Black non-Hispanic transit riders account for $26.5 \%$ of all transit trips in 2017 , and the Hispanic population accounts for $19.3 \%$ of 2017 transit ridership. All other races account for $14.3 \%$ of transit trips, which includes persons of two-or-more races. This data indicate declines in Black and Hispanic market shares and an increase in the White market share. This finding is consistent with some of the changes in income and age that showed up in prior graphs. To the extent that the sample weighting is correct, this confirms evolution of the transit market. 


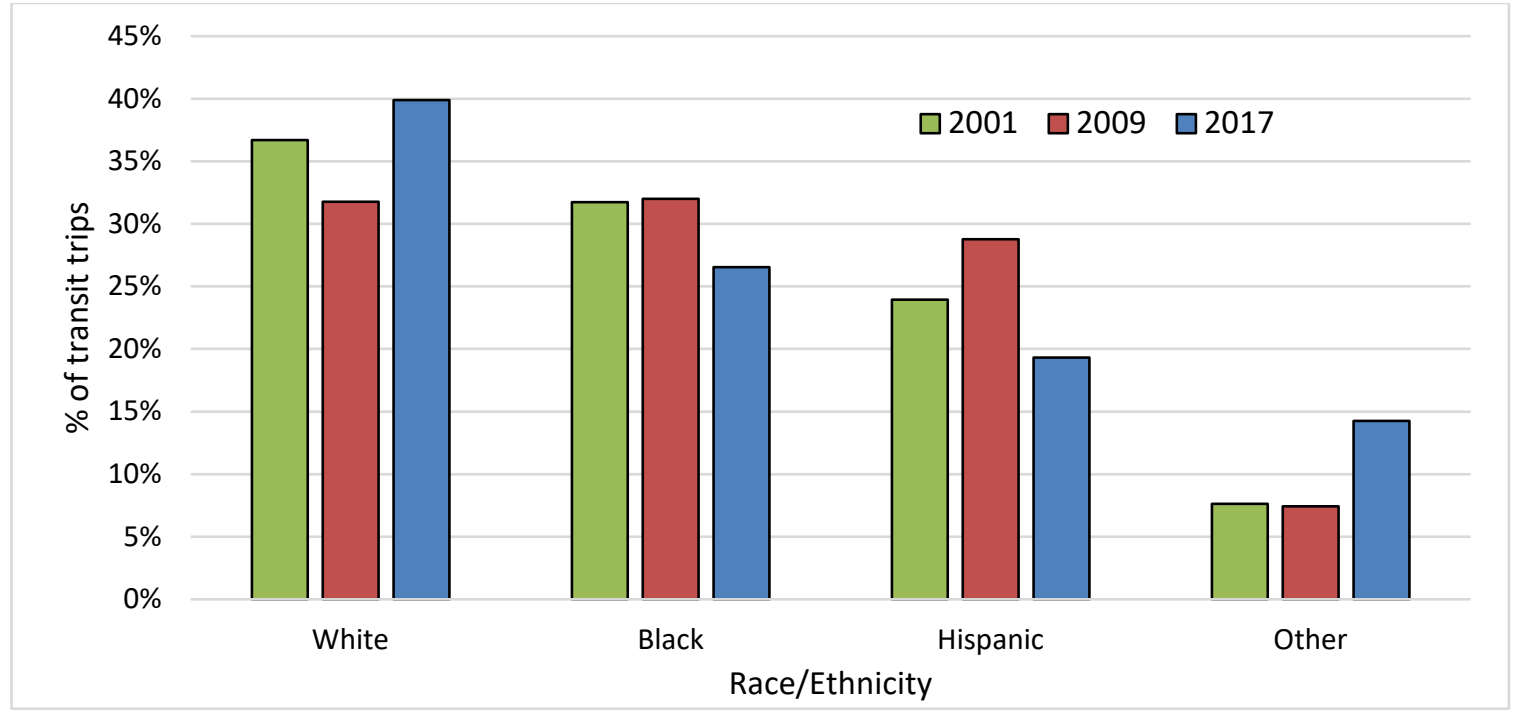

Figure 21. Percent of Transit Trips by Race

\section{Public Transportation and Urban Classification Distribution}

Figure 22 reports the urban/rural mode share trends. Given the overall increase in mode share embedded in the NHTSA 2017 data, the increase in mode share for the dominant urban segment of the population is to be expected. The transit mode share for urban travelers increased from $2.4 \%$ in 2001 and 2009 to $3.0 \%$ in 2017. The rural mode share decreased from $0.5 \%$ in 2001 to $0.2 \%$ in 2009 and 2017 . This figure helps to verify that the increased transit mode share that was reported in the 2017 NHTS was focused in urban settings.

\section{Public Transit and Transportation Network Company Travel (TNC)}

The 2017 NHTS was the first time that transportation network companies (TNCs, services such as Uber and Lyft that provide smart phone ride hailing services) were captured in the NHTS. This is an important factor to consider when discerning the results of TNC use in the NHTS survey, and especially as comparisons are made between ride hailing transportation over 
various survey years. The emergence of ride hailing services occurred around $2009^{4}$, resulting in miniscule TNC representation, at best, in the 2009 NHTS data, which included travel between March 28, 2008 and April 30, 2009. Therefore, any comparisons of taxi/TNC use over time are most useful to discern the differences in the types of trips that are taken by the two modes. It is also not appropriate to make direct comparisons of taxi use from the 2009 NHTS survey to the 2017 NHTS survey, given the inclusion of TNC travel in the taxi category in 2017. Additionally, it is important to remember that TNC use, even at the peak age group, accounts for less than one percent of all total trips, making the sample size susceptible to larger standards of error. TNC use is of interest to public transportation stakeholders in that it both competes with and compliments public transportation with the body of evidence suggesting it is contributing to soft transit ridership in several cities ${ }^{5}$. According to a recent study, about a third of TNC trips would be made via public transit if TNC were not available, suggesting that TNC use is substituting transit trips, at least some of the time ${ }^{6}$. On the other hand, TNCs appear to be penetrating neighborhoods with poor transit coverage and low car ownership, and transit partnerships with TNC companies have the potential to attract riders that would not otherwise have access to transit ${ }^{7}$. Those that reported TNC use in the 2017 NHTS tend to be younger, more educated, higher-earning, urban dwellers ${ }^{8}$. TNC use was integrated with Taxi use in NHTS travel diary questions but TNC use dominates the use of hailed services. Figure 23 shows the share of trips made on hailed services in the various survey years. The distinctive pattern for 2017 and its significantly higher level of use reflects the emergence of TNCs. Given TNC use has supplanted a significant share of the taxi market and given the higher total hailed trip shares reported in 2017, one can discern the significance of the addition of TNC services. Figure 23 also gives insight into the extent of reliance on TNC services for various age cohorts.

\footnotetext{
${ }^{4}$ Clewlow, Regina R. and Mishra, Gouri Shankar. Disruptive Transportation: The Adoption, Utilization, and Impacts ofRide-Hailing in the United States. Institute of Transportation Studies, University of California, Davis. October 2017. https://escholarship.org/uc/item/82w2z91i

${ }^{5}$ Understanding Ridership Trends in Transit, Final Report, Prepared for: Florida Department of Transportation, Transit Office, Steven Polzin and Jodi Godfrey, Center for urban Transportation Research, February 2019, https://www.cutr.usf.edu/wp-content/uploads/2019/03/508complete understandingridershiptrendsintransit.pdf, pp. 65-76.

${ }^{6}$ Ridesourcing's Impact and Role in Urban Transportation. Susan Shaheen, Nelson Chan, and Lisa Rayle, University of California, Berkeley. Access Magazine, Spring 2017. http://www.accessmagazine.org/wpcontent/uploads/sites/7/2017/05/Shaheen-Rayle-and-Chan-Access-Spring-2017.pdf

${ }^{7}$ Where Ride-Hailing and Transit Go Hand in Hand .Laura Bliss. Citylab. August 3, 2018. https://www.citylab.com/transportation/2018/08/where-ride-hailing-and-transit-go-hand-in-hand/566651/ ${ }^{8}$ Socioeconomic and Usage Characteristics of Transportation Network Company (TNC) Riders. Rick Grahn, Corey D. Harper, Chris Hendrickson, Zhen Qian H, Scott Matthews. Springer. April 22, 2019.

https://doi.org/10.1007/s11116-019-09989-3
} 


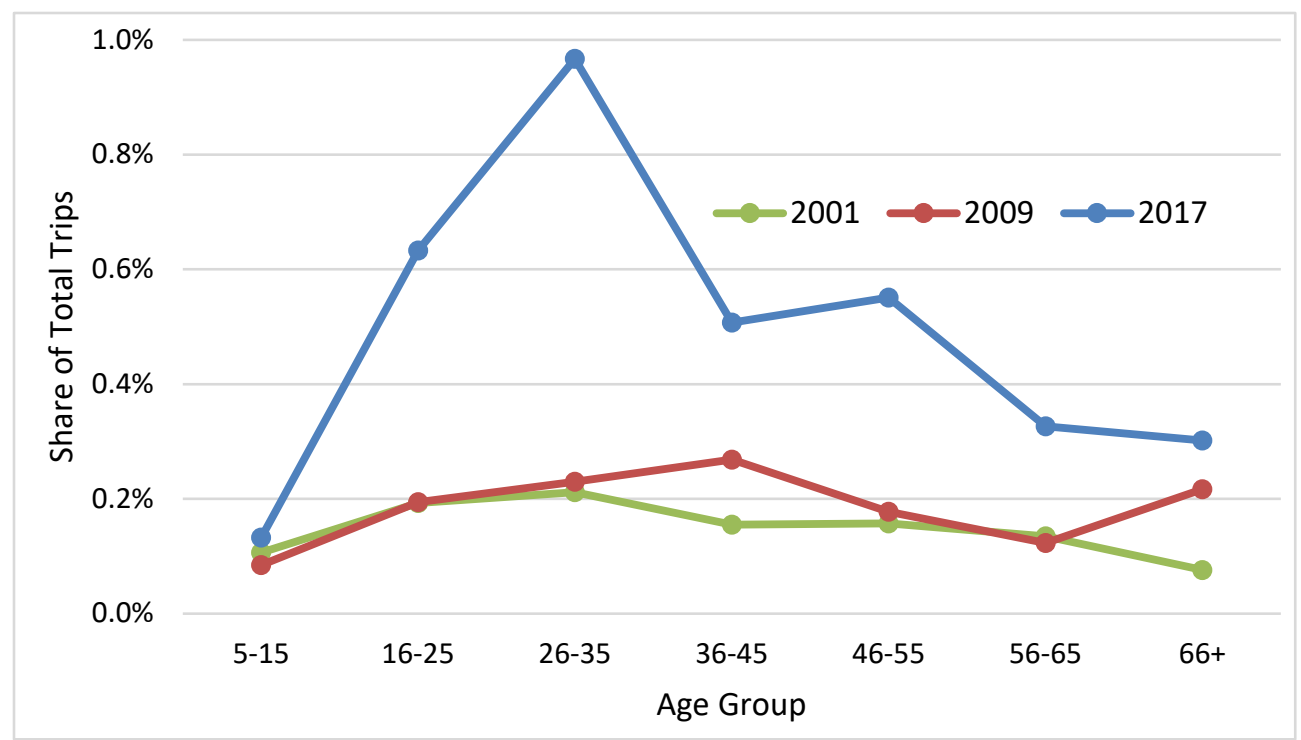

Figure 23. Share of Total Trips Made on "Taxi" Mode by Age Group

Figure 24 shows the distribution of TNC trips by age group. As the graphic reveals, TNC use is occurring across all age cohorts.

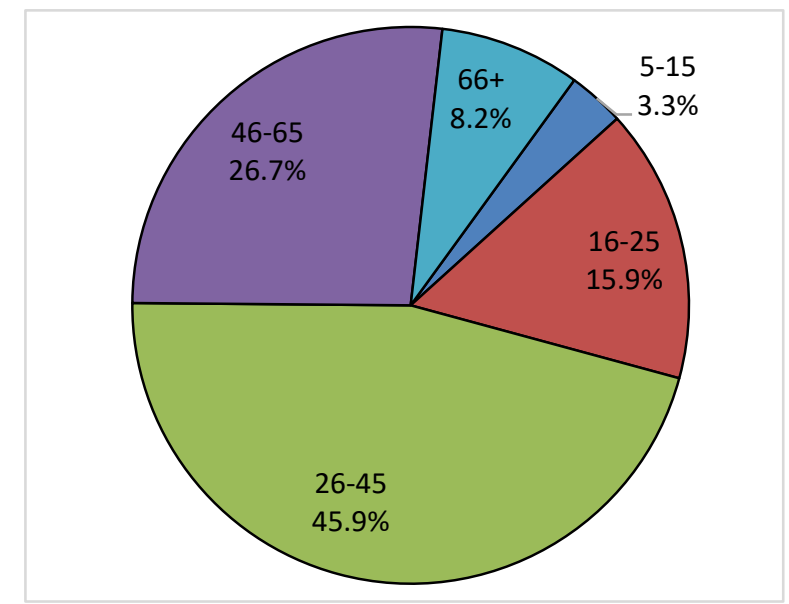

Figure 24. Share of All Taxi/TNC Trips by Age, 2017

Figure 25 portrays the mode share for public transit and TNC/taxi by age group. TNC use peaks for a slightly older age cohort before dropping off modestly with age. Transit use similarly declines beyond age 35 but ticks up for $66+$-year-olds. Figure 26 portrays the share of travel by the respective modes by age cohort. For both modes the 26 to 45 -year-old age bracket comprises the largest share of travelers (note: age brackets are not the same size). 


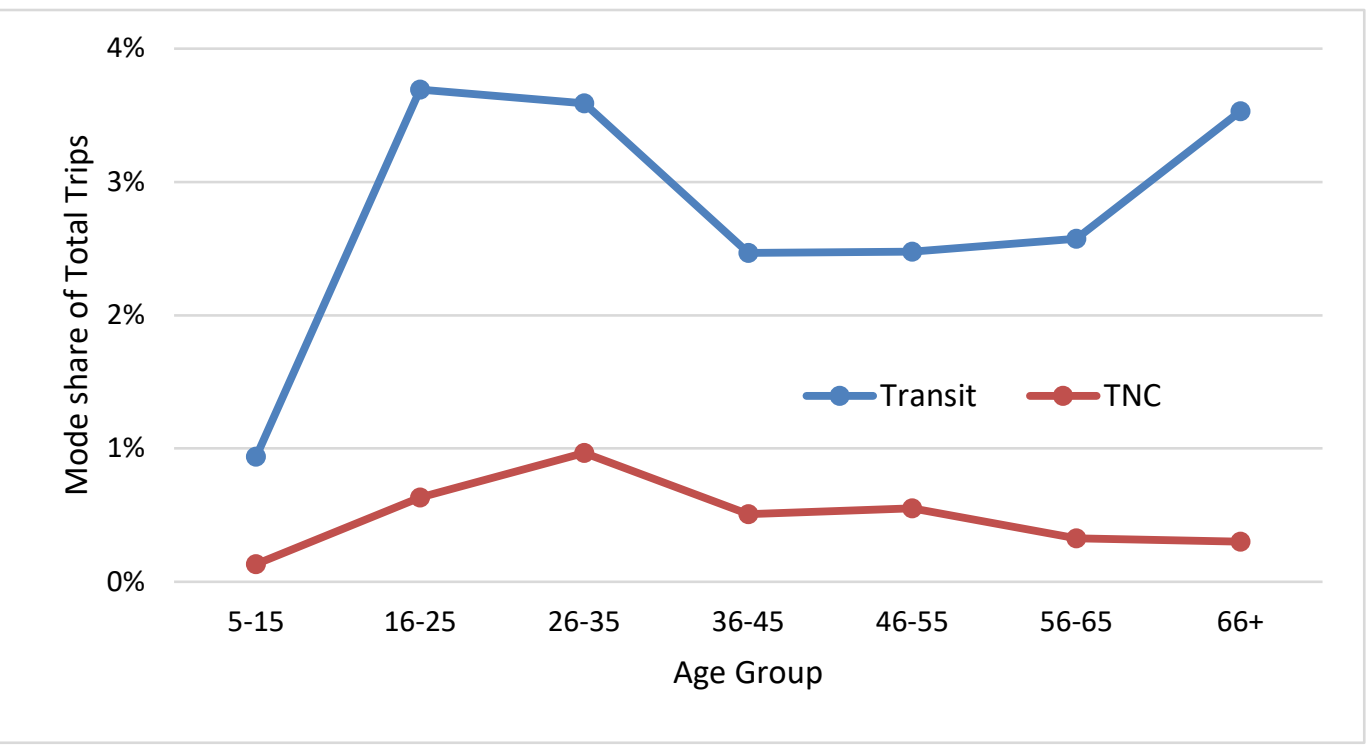

Figure 25. Transit and TNC Mode Share of Total Trips by Age Group, 2017

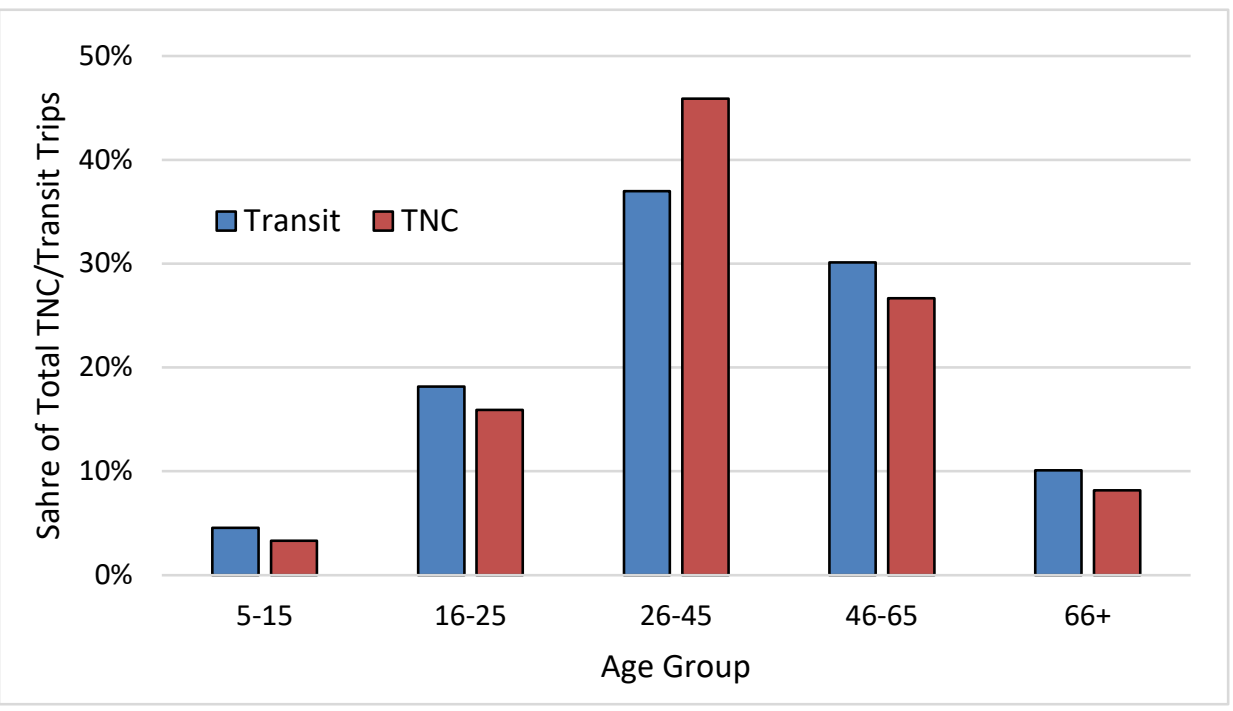

Figure 26. Share of TNC/Transit Trips by Age Group, 2017

Figure 27 presents TNC/taxi trips as a percent of all trips and all trip purposes for 2009 and 2017. The growth in the various categories shows areas where hailed services have increased market penetration since the emergence of TNC services. Most striking is the growth in workrelated business. 


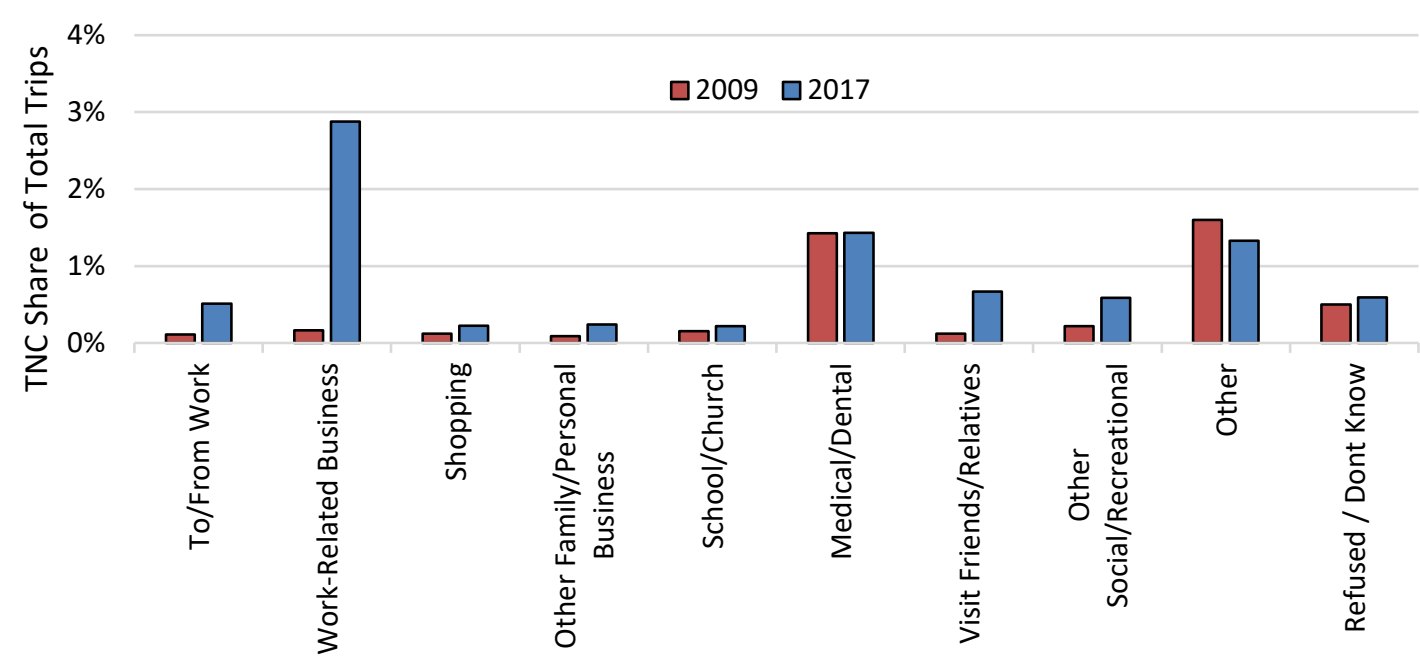

Trip Purpose

Figure 27. Trip Purpose Distribution Trend for Taxi/TNC Trips

Figure 28 presents the trip purpose distribution for transit and TNC/taxi trips. The percentages are expressed as a share of all trip purposes and all trip modes. In all purpose categories transit is more frequently used than are TNC services. TNC is most competitive in work-related business travel. In these contexts, the traveler may be in a position to expense travel costs and may be more sensitive to the time cost of travel than is the case for personal use of TNCs.

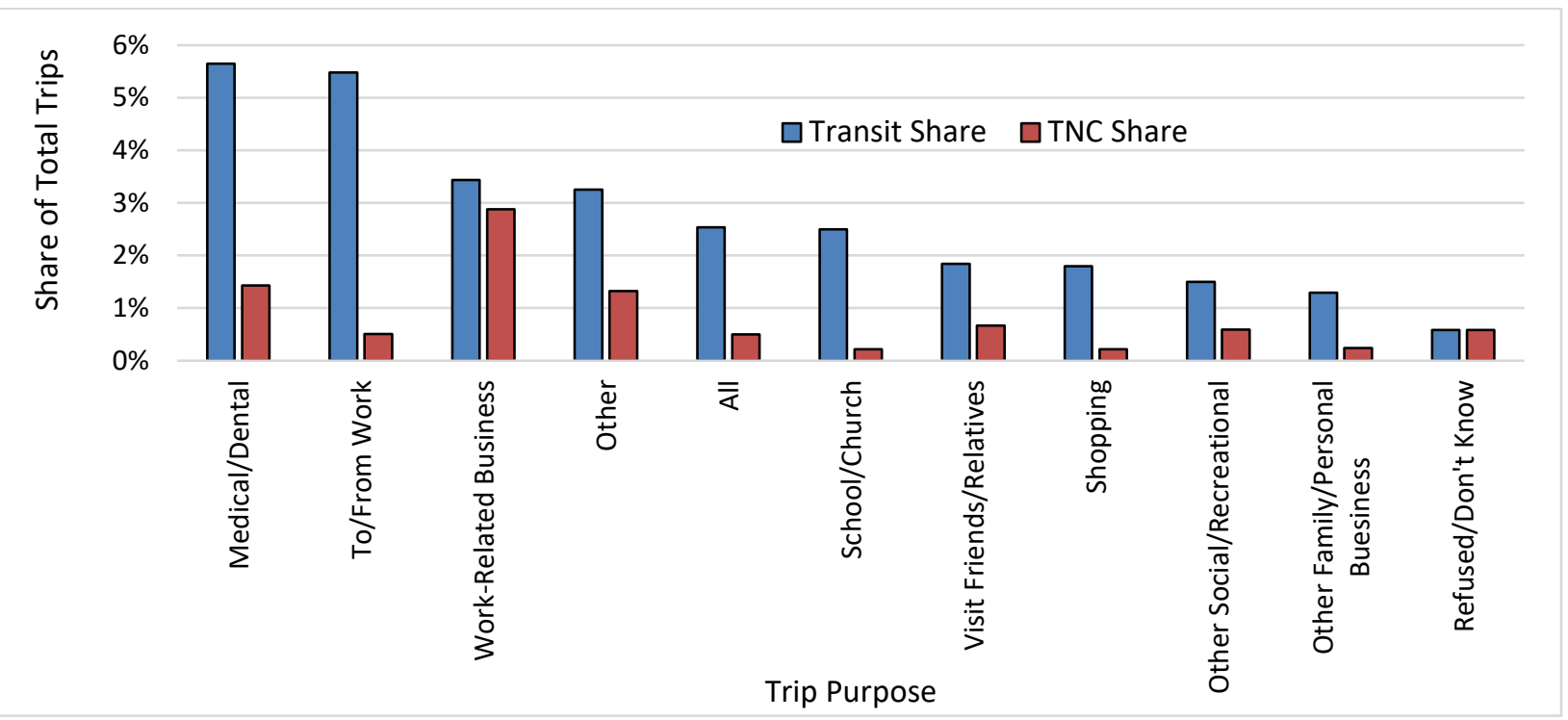

Figure 28. Mode Share Distribution for TNC and Transit Trips by Trip Purpose, 2017

Figure 29 shows that same trip purpose distribution for public transit trips. The most pronounced changes in relative mode share between the survey years occurs for work and 
work-related trips, medical dental trips, and other trip purposes. Transit use declined in mode share for visiting friends and relatives and "other" trip purpose but was higher for all other purpose categories.

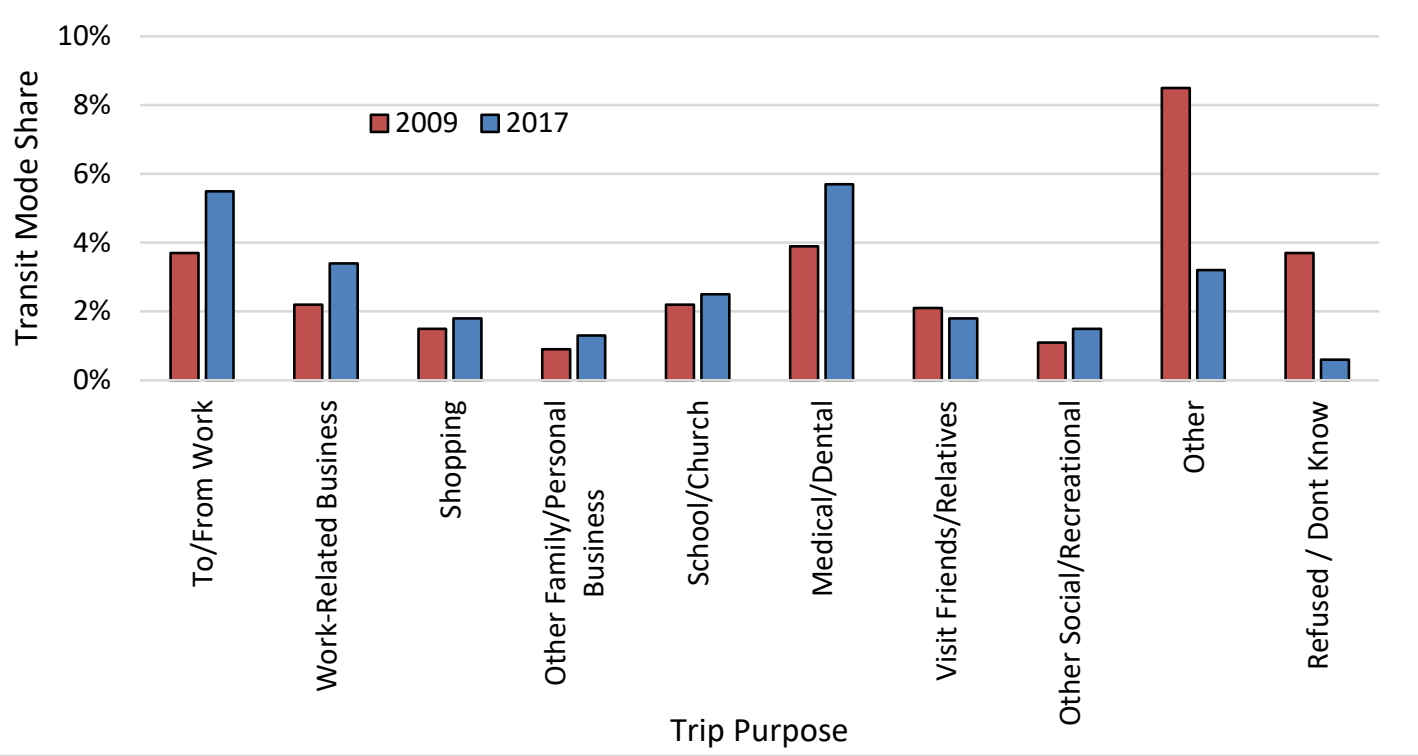

Figure 29. Trip Purpose Distribution Trend for Public Transit Trips

In addition to reporting TNC use in the travel diary, the survey also queried respondents regarding their use of TNC within the past 30 days. Figure 30 enumerates respondents who reported TNC use and those that reported TNC use who also reported transit use on their travel day.

\section{Of those}

respondents who use public transit on their travel day, $30 \%$ reported using TNC's within the last 30 days. Transit users are about three time more likely to use TNC services than is the general public.

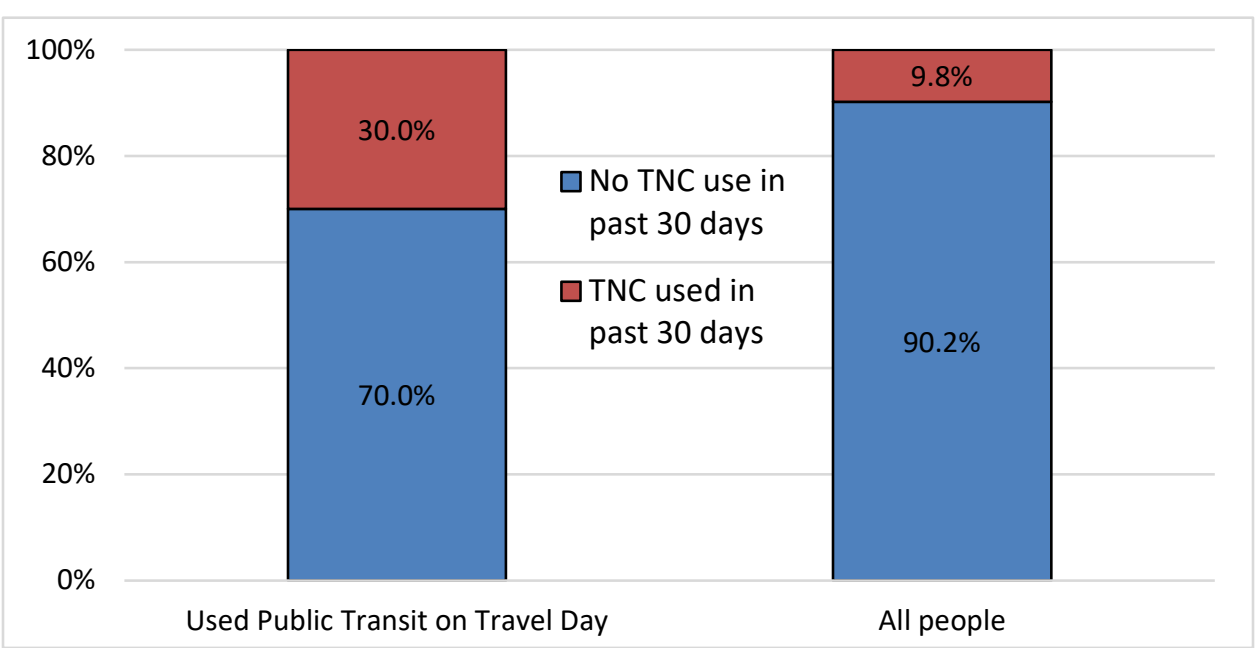

Figure 30. Share of Public Transit Users Who Used Rideshare App in Past 30 Days, 2017 


\section{How Competitive Is Public Transportation?}

Recent ridership trends in public transportation have given rise to a growing interest in understanding the competitiveness of public transportation. There are a host of traits that travelers might use when determining mode choice including things like cost, image, reliability, flexibility, availability and others that are not clearly discernable with NHTS data. However, there are some traits relating to travel speed and travel time that can be extracted from NHTS data and add insight into transit's competitiveness. Figure 31 compares the components of the average trip time for public transit trips in 2009 with 2017 NHTS survey data. The total average transit trip time increased $13.8 \%$ from 2009 to 2017, with the greatest change in the time component related to time spent in the vehicle. Wait time was the only time component that was longer in 2009 at an average of 9.86 minutes, compared to an average 9.39 minute wait time in 2017, a decrease of $4.7 \%$. Figure 32 displays the difference in the components of times of transit trips dependent upon whether or not at least one transfer occurred on the trip. According to survey respondents, in-vehicle time for individuals whose trip involves a transfer constitutes slightly more than half the total travel time. For trips that did not show a transfer about 42 percent of travel time was in-vehicle time. These numbers suggest that the competitiveness of public transit is affected by both in vehicle travel time but also out of vehicle time. This out of vehicle time is less likely to be able to be deployed productively (rest, read, etc.) and more likely to expose the traveler to the elements or safety risks than in-vehicle time.

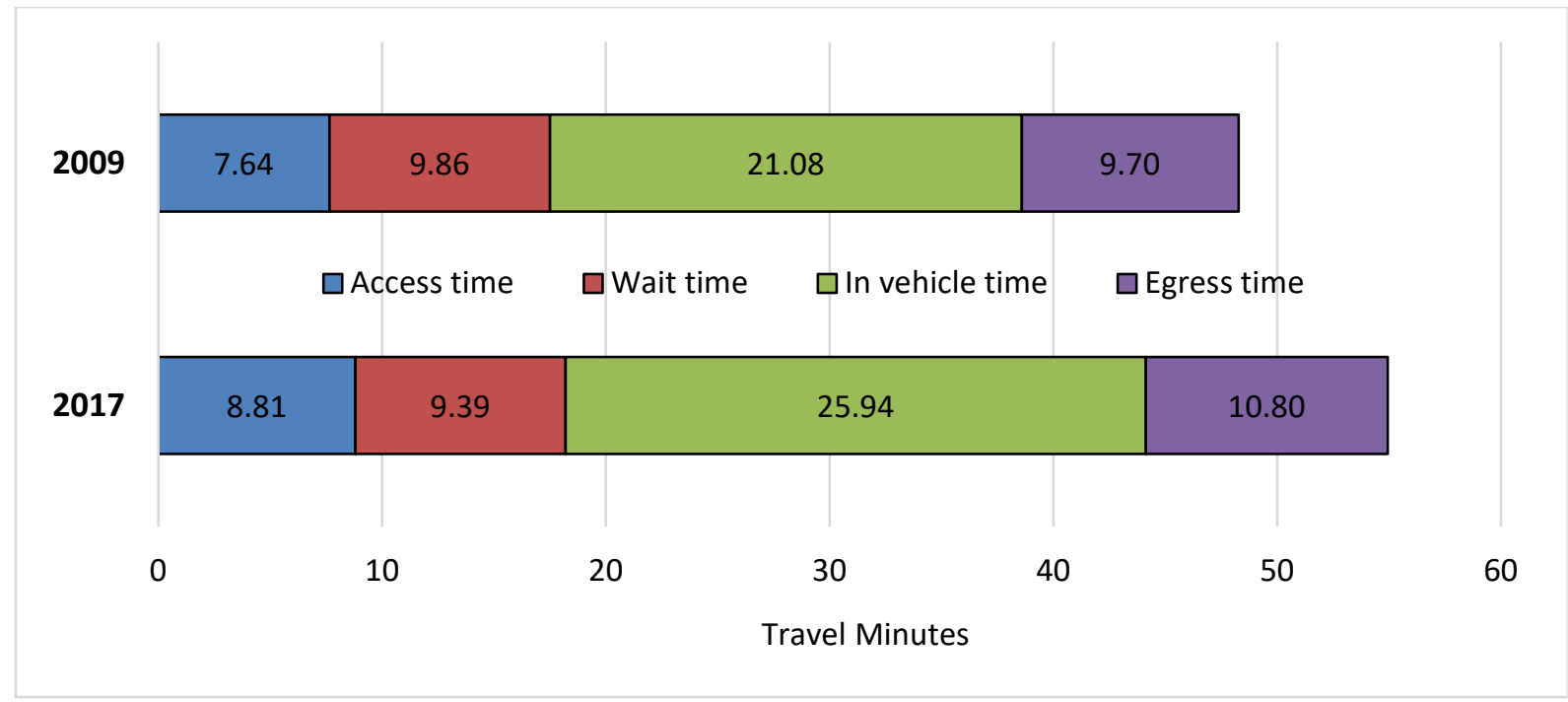

Figure 31. Average Transit Travel Time Components, 2009 to 2017 Comparison 


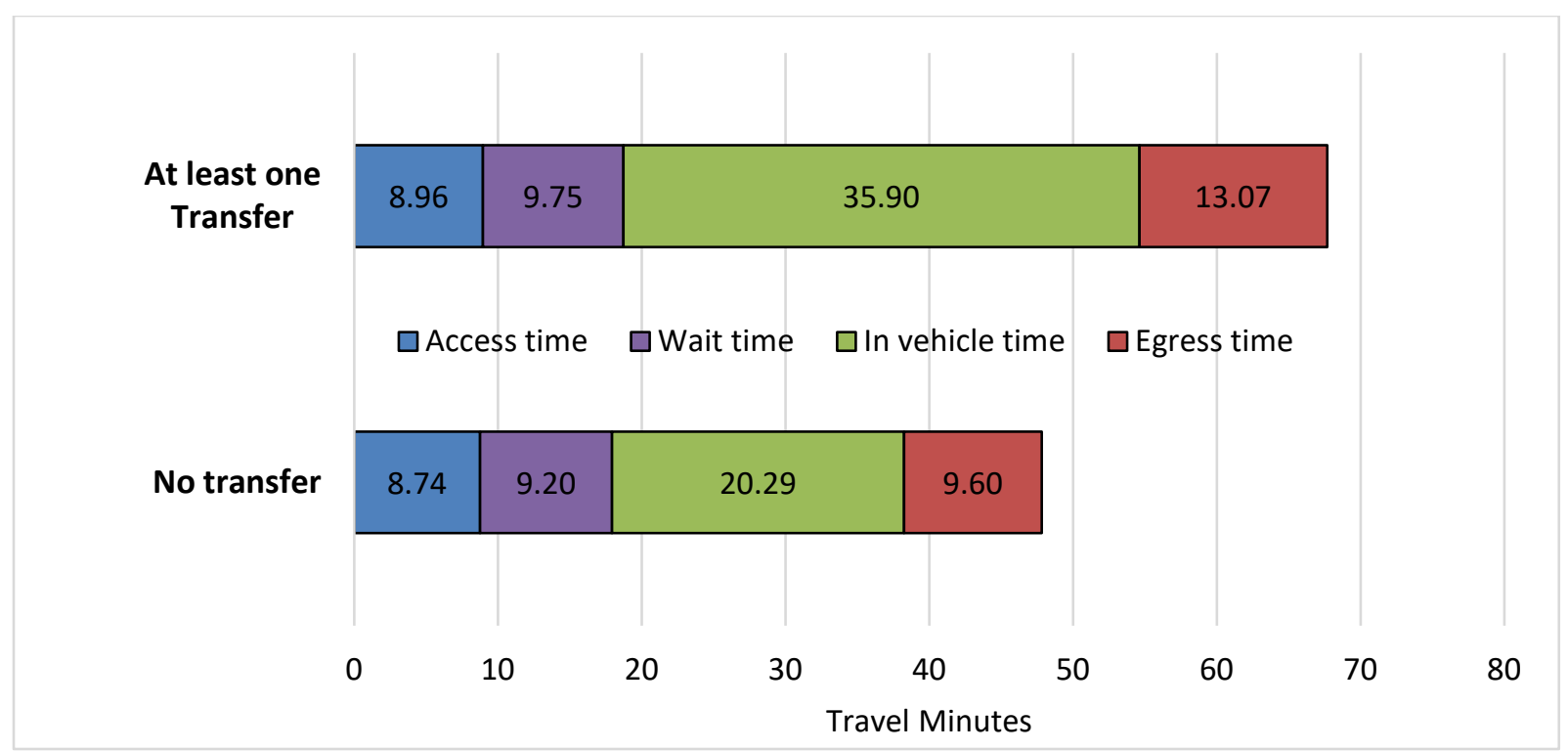

Figure 32. Average Transit Travel Time Components for Trips by Transfers, 2017

Figure 33 shows travel speeds for transit travel by metro area size and survey date. These speeds, extracted from respondent reported travel times, point out the well-recognized fact that public transit travel is substantially slower than other modal travel speeds. When burdened by the need to access and egress the service, wait for the vehicle to arrive, travel via a route that may or may not be a most direct travel path, potentially have to transfer to another bus or rail, and typically stop at interim locations to allow other passengers to access and egress the vehicles, in aggregate, transit travel results in substantially slower travel for the average personal vehicle traveler. The average speeds of personal occupant vehicles (POVs) are displayed in Figure 34 as a comparison to the average transit speeds displayed in Figure 33. Just as the average transit speed decreases as the MSA size increases, the average travel speed for POVs also decreases. However, the average POV speed for the densest MSA is still faster than the average speed of transit in the least dense MSA. The smaller sample size of transit travel in the NHTS survey should remain in consideration as sampling limitations have the potential to reflect greater fluctuation in travel speed, especially in the data examination through multiple subcategories. 


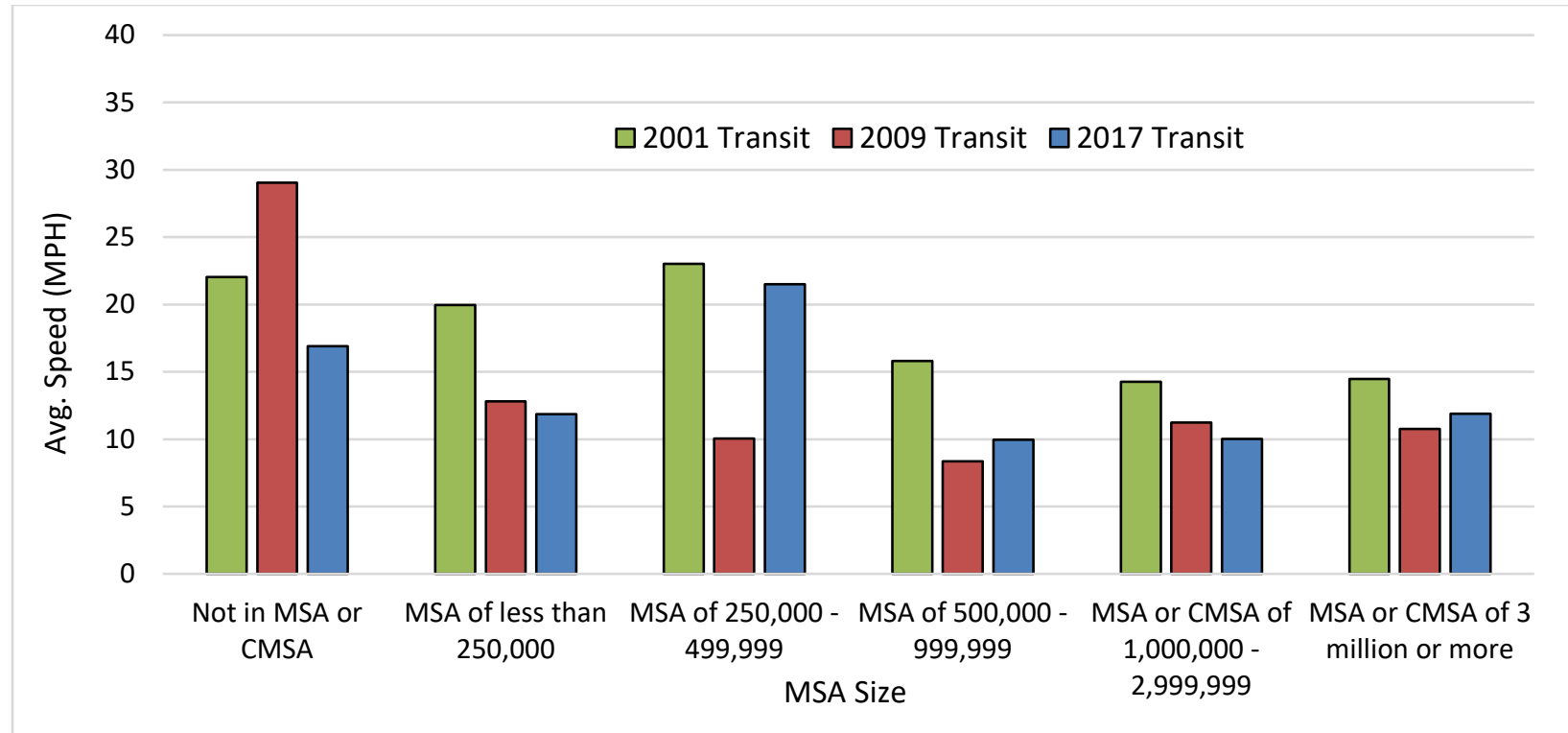

Figure 33. Average Transit Trip Speed Trend by Metro Area Size

Note: The average trip length is suspiciously high for the MSA size of $250,000-499,999$, leading to a greater than expected trip speed. The average trip public transit trip length equals 8.8 miles, while the average public transit trip in an MSA of 250,000 to 499,999 equals 21.5 miles.

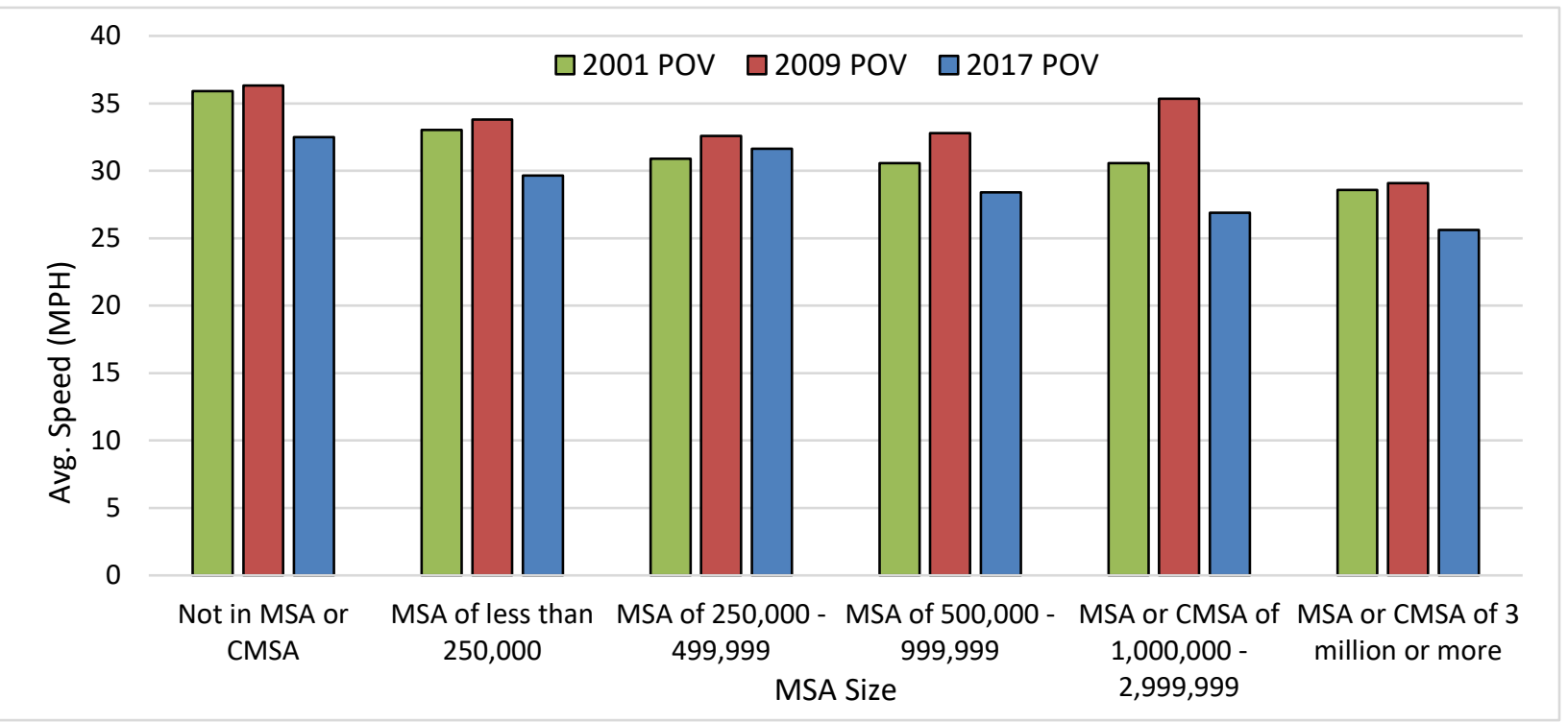

Figure 34. Roadway Trip Speed Trend by Metro Area Size

Figure 36 and Figure 35 present the speed trend and sub mode distribution for public transit. Rail is getting a little faster, no doubt related to the expansion of services to outlying areas where running times are higher and station stops are less frequent. Bus speeds are declining as would be expected given the increased urban congestion levels since 2001. Exclusive guideways and service purposes impact the operating speeds of sub modes. 


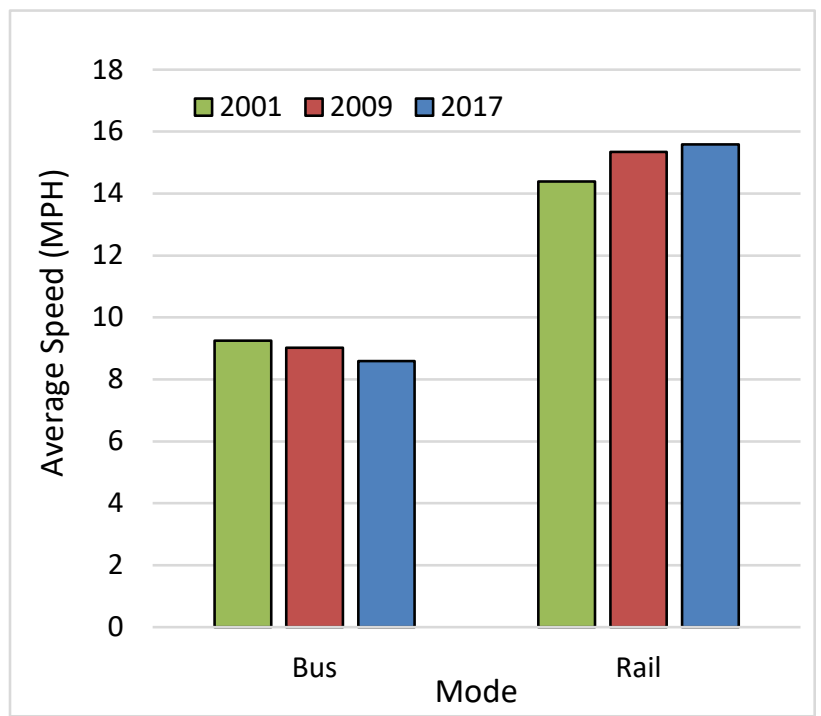

Figure 36. Transit Trip Speed Trend by Sub Mode

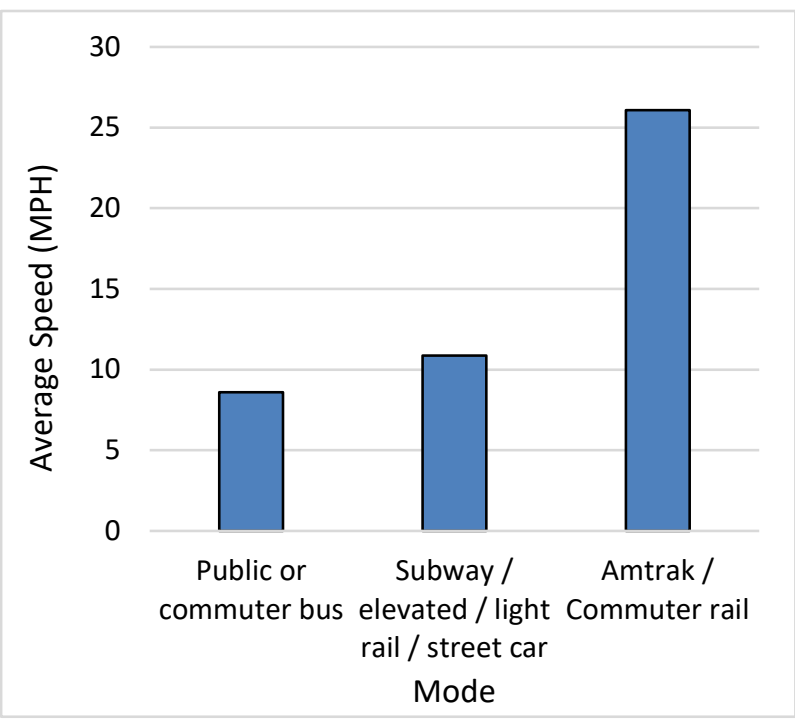

Figure 35. Transit Trip Speed by Sub Mode, 2017

\section{Summary and Conclusions}

Taking some of the methodological changes of the data collection methods of the survey into account, and understanding the potential impact of those changes as data is compared over time, is one important aspect that should not be overlooked in the data analysis. Declining trip rates were likely influence by the methodology changes, along with trip lengths. The data also revealed that transit trips were high and vehicle trips were low, which is speculated by this research team to be at least partially attributable to oversampling of high density rail transit environments. As such, the changes in transit trip characteristics over time, were limited in this analysis, and should be considered with caution if future analyses consider further subcategorization.

Understanding the market opportunities for public transportation is of particular interest to transportation planners. The information presented in Figure 2 through Figure 5 indicate changes in the profile of transit travelers both with respect to travel mode and with respect to income distribution of transit travelers. This change, while interpreted cautiously due to sample size and weighting issues, has a number of potential implications to public transportation going forward. The evidence suggests that higher income travelers are comprising a larger share of transit users and that they are, in particular, utilizing rail services. This can be explained partially by geographic orientation of these services and their relative competitiveness with alternative means of travel. This trend has significant implications both in terms of targeting market growth opportunities but also in terms of planning and policy implications that relate to the fundamental purposes of providing public transportation and the distribution of benefits 
associated with the provision of public transportation. These implications may merit reflection when making decisions about service pricing, funding and service allocation/investment priorities.

Rail services are capital-intensive, thus the distribution of direct benefits to travelers and indirect benefits to landowners and businesses are relevant policy issues. Similarly, transit pricing, historically influenced by the desire to remain affordable for low income travelers and the ability to pay before boarding for fare collectors, may also merit restructuring given emerging rider profiles. In the extreme, transit is providing more service on capital-intensive systems that provide higher performance and succeeding in attracting a higher income profile users. In the meantime, bus services are slowing and evidence mounts that low-income households are increasing vehicle ownership - a trend that undermines transit use as borne out by the data in Figure 6.

There is other evidence in Figure 14 - Figure 22 of shifts in the profile of transit users. They are shifting older, whiter, more male and more urban. These traits are consistent with the shift in income distribution and the shift in sub mode use. Interestingly, the increase in choice travelers, while modest, occurred when new travel options such as TNC are available to choice travelers as are options to replace travel with communication. In addition, these trends have occurred in spite of the expectation that these market segments may be more sensitive to concerns for service reliability, safety, and cleanliness/comfort including exposure to homeless persons or persons with mental health or substance abuse challenges that can deter choice travelers. Evidence of growth in choice travelers is somewhat surprising considering the media attention to service conditions in several high ridership operating markets.

Public transportation appropriately strives to attract new riders and offer benefits to the full spectrum of the population; however, public investments are appropriately subject to scrutiny with respect to equity and the implications of the distribution of costs and benefits of providing public services. The evidence in shift in markets coupled with the sensitivity to equity of many stakeholders may give rise to additional discussions of the implications to policies governing the provision, pricing and funding of public transit going forward.

The NHTS data set provides an opportunity to gain insight on TNC users and begin to explore interrelationships between public transportation and TNC use. Top transit cities are also top cities for TNC use. The conditions conducive to not using personal vehicles such as very highpriced parking and being away from home on business travel, make alternatives such as TNC and public transportation more viable. TNC use has a somewhat similar age profile as does transit use but has particularly gained market share for business- and business-related travel. This is not surprising as employer compensated/reimbursed trip making would not have the same price sensitivity as might personal travel and persons engaged in professional activities 
may have a higher travel time value sensitivity that could favor TNC use in instances where it provided faster door-to-door travel time than public transportation.

It's important to remember that the TNC business model is rapidly evolving and that the NHTS data set is between two and three years old as of early 2019, thus, the TNC mode has grown dramatically and incurred numerous changes in pricing and service delivery characteristics since this data was collected. In instances where personal auto travel is disadvantageous, TNC and public transportation will be competitors for travelers' business. TNCs primary opportunities to be complementary are in cases where they serve as first-mile/last-mile connectors or contract operators/providers for targets markets such as paratransit services. In a more general context, TNCs have the potential to be complementary to public transit in cases where they result in households relinquishing a vehicle or vehicles such that public transit becomes a more competitive options in more travel situations.

The final topic area addressed in this report was a summary look at the competitiveness of public transportation with respect to some of the metrics that can be extracted from NHTS data. Travel speed is a critical factor in mode choice and, not surprisingly, roadway speeds have declined since prior survey years. The evidence on transit speeds is mixed with bus slowing some and rail getting a little faster. The comparative data on the components of overall travel time on transit shows that the largest share of the increase in average transit trip times between 2009 and 2017 is attributable to in vehicle travel time. Access and egress times also increased on average from 2009 , but the average wait time decreased slightly. The overall transit travel time increased $13.8 \%$ in 2017.

The collective consequence of the information presented suggests analysts continue to monitor evolution of the transit market and transit's competitiveness going forward. The data provides some strong evidence of changes that appear consistent with broader socioeconomic and demographic phenomenon and transit service deployment initiatives in recent years. However, the modest samples and challenges in garnering accurate data via surveys in an era where finding responsive survey participants is increasingly challenging favors being cautious in over interpreting the significance of these data independently. Individual agencies may find these observations insightful and can utilize other data sets such as the American Community Surveys and onboard or local household travel surveys to further test the veracity of some of the observations that are derived from this analysis.

It is important to note that there has been a historic interest in "national average" information about transit performance and transit users and such information may be relevant in informing national policies with respect to public transportation. However, there is growing evidence that the purposes, performance, and market characteristics for public transportation are increasingly diverse across metropolitan areas. Accordingly, national trends and observations 
may be less relevant given the variation in trends across geography. Disentangling the cause and effect of trends in public transportation are best informed by more in-depth analysis at the local level with national data serving as a starting point for defining potential issues of interest or positioning a given Metro area with respect to aggregate national trends. 


\section{References}

2017 NHTS Data User Guide. March 8, 2018. Accessed https://nhts.ornl.gov/assets/2017UsersGuide.pdf

An Assessment of Public Transportation Markets Using NHTS Data, Xuehao Chu, Ph.D., Florida Department of Transportation (2012). Accessed: https://www.nctr.usf.edu/wpcontent/uploads/2013/01/77920.pdf

National Transit Database Data. Accessed: https://www.transit.dot.gov/ntd/ntd-data

Public Transit in America: Analysis of Access Using the 2001 National Household Travel Survey, Steven Polzin, Xuehao Chu, Edward Maggio. Florida Department of Transportation, December 2006. Accessed: https://www.nctr.usf.edu/pdf/576-02.pdf

Public Transit in America: Findings from the 1995 Nationwide Personal Transportation Survey, Steven Polzin, Joel Rey, Xuehao Chu. National Urban Transit Institute (1998). https://trid.trb.org/view/537691

Public Transit in America: Results from the 2001 National Household Travel Survey, Steven Polzin, Xuehao Chu. Final Report, National Center for Transit Research (2005). Accessed: https://www.nctr.usf.edu/pdf/527-09.pdf

Ridesourcing's Impact and Role in Urban Transportation. Susan Shaheen, Nelson Chan, and Lisa Rayle, University of California, Berkeley. Access Magazine, Spring 2017. http://www.accessmagazine.org/wp-content/uploads/sites/7/2017/05/Shaheen-Rayleand-Chan-Access-Spring-2017.pdf

Socioeconomic and Usage Characteristics of Transportation Network Company (TNC) Riders, Rick Grahn, Corey D. Harper, Chris Hendrickson, Zhen Qian, H. Scott Matthews. Springer. April 22, 2019. https://doi.org/10.1007/s11116-019-09989-3

Summary of Travel Trends. 2017 National Household Travel Survey. Federal Highway Administration. N. McGuckin and A. Fucci. July 2018. Accessed: https://nhts.ornl.gov/assets/2017 nhts summary travel trends.pdf

Transit Trends Analysis, FHWA. 2017 National Household Travel Survey, February 2019. Accessed: https://nhts.ornl.gov/assets/FHWA NHTS Report 3A Final 021119.pdf

Understanding Ridership Trends in Transit, Final Report, Prepared for: Florida Department of Transportation, Transit Office, Steven Polzin and Jodi Godfrey, Center for urban Transportation Research, February 2019, https://www.cutr.usf.edu/wp- 
content/uploads/2019/03/508complete understandingridershiptrendsintransit.pdf, pp. 65-76.

U.S. Census Bureau. American Community Survey Table B25001, 2016. Accessed: https://factfinder.census.gov/faces/nav/isf/pages/index.xhtml

U.S. Department of Transportation, Federal Highway Administration, 2001 National Household Travel Survey. Accessed: https://nhts.ornl.gov.

U.S. Department of Transportation, Federal Highway Administration, 2009 National Household Travel Survey. Accessed: https://nhts.ornl.gov.

U.S. Department of Transportation, Federal Highway Administration, 2017 National Household Travel Survey. Accessed: https://nhts.ornl.gov.

Where Ride-Hailing and Transit Go Hand in Hand. Laura Bliss. Citylab. August 3, 2018. https://www.citylab.com/transportation/2018/08/where-ride-hailing-and-transit-gohand-in-hand/566651/ 